\title{
Atom Probe Tomography for Catalysis Applications: A Review
}

\author{
Cédric Barroo ${ }^{1,2,3, *} \mathbb{C}^{\text {, Austin J. Akey }}{ }^{4}$ and David C. Bell ${ }^{3,4}$ \\ 1 Chemical Physics of Materials and Catalysis, Université Libre de Bruxelles, CP 243, 1050 Brussels, Belgium \\ 2 Department of Chemistry and Chemical Biology, Harvard University, 12 Oxford Street, Cambridge, \\ MA 02138, USA \\ 3 Harvard John A. Paulson School of Engineering and Applied Sciences, Harvard University, 29 Oxford Street, \\ Cambridge, MA 02138, USA \\ 4 Center for Nanoscale Systems, Harvard University, 11 Oxford Street, Cambridge, MA 02138, USA \\ * Correspondence: cbarroo@ulb.ac.be
}

Received: 29 May 2019; Accepted: 29 June 2019; Published: 5 July 2019

check for updates

\begin{abstract}
Atom probe tomography is a well-established analytical instrument for imaging the 3D structure and composition of materials with high mass resolution, sub-nanometer spatial resolution and ppm elemental sensitivity. Thanks to recent hardware developments in Atom Probe Tomography (APT), combined with progress on site-specific focused ion beam (FIB)-based sample preparation methods and improved data treatment software, complex materials can now be routinely investigated. From model samples to complex, usable porous structures, there is currently a growing interest in the analysis of catalytic materials. APT is able to probe the end state of atomic-scale processes, providing information needed to improve the synthesis of catalysts and to unravel structure/composition/reactivity relationships. This review focuses on the study of catalytic materials with increasing complexity (tip-sample, unsupported and supported nanoparticles, powders, self-supported catalysts and zeolites), as well as sample preparation methods developed to obtain suitable specimens for APT experiments.
\end{abstract}

Keywords: atom probe tomography; APT; FIB sample preparation; alloy engineering; core-shell structure; nanoporous catalyst; zeolite; correlative techniques

\section{Introduction}

Current trends in designing the size, shape and composition of catalytic nanoparticles to improve their selectivity and efficiency require understanding catalytic processes at the nanoscale. For this, it is of utmost importance to understand how the morphology and composition of the catalysts evolve during the reaction, the equilibrium-shape of the catalyst under reaction conditions, and the factors controlling the reliability of the process. For molecular analysis of a catalyst, high-resolution imaging techniques are necessary. Tomography techniques are particularly valuable to the study of both the surface and the bulk structure and composition of catalytic materials. Neutron tomography [1] and X-Ray microtomography [2-4] have only been used to a small extent to study catalytic materials due to their lower resolution, but there is growing interests in the study of catalysts by electron tomography [5-7] and atom probe tomography [8]. Atom probe tomography is part of the field emission techniques, which comprise the Field Emission Microscopy (FEM), Field Ion Microscopy (FIM) and Atom Probe Tomography (APT). These techniques can characterize materials with atomic scale resolution; one of the required conditions is to have specimens prepared as sharp tips since a high electric field is required to induce the relevant emissive behavior (either field emission, field ionization or field evaporation $[9,10])$.

FEM and FIM have been used to study model catalysts prepared as APT tip specimens: the reactions are performed under well-controlled reactive conditions and on catalysts of well-defined size, 
shape and morphology. Due to the tip-shape of the specimen, several facets of different crystallographic orientation are exposed at the same time, and the apex can thus be seen as a model of a single nanoparticle. FEM and FIM are used to image the surface before and after reaction, but also under reactive conditions, which makes these techniques particularly suited for the study of catalytic systems. This allows the characterization of the morphological reconstructions of the surface, as well as the dynamical processes occurring during the ongoing catalytic reactions. The studied systems consist mainly in reactions of interest for automotive pollution control on platinum group metal catalysts: $\mathrm{CO}$ oxidation [11-13], $\mathrm{O}_{2}$ hydrogenation [14-16], $\mathrm{NO}$ hydrogenation [17-19] and $\mathrm{NO}_{2}$ hydrogenation [20-23]. There is however no direct chemical information available with FEM and FIM microscopes, and atom probe techniques were developed to overcome this issue. Early atom probe designs consisted in the coupling of a FIM microscope with a mass spectrometer, bearing the name of atom probe field ion microscopy (APFIM), 1-dimensional atom probe (1DAP) or pulsed field desorption mass spectrometry (PFDMS). These instruments allow simultaneous in situ imaging and analysis by mass spectrometry of the adsorbate layer or the near-surface layers over a small and well-defined region of the specimen $\left(\sim 10 \mathrm{~nm}^{2}\right)$. This permits the study of surface segregation in different alloys: $\mathrm{Pt}-\mathrm{Ir}, \mathrm{Ni}-\mathrm{Cu}, \mathrm{Pt}-\mathrm{Au}, \mathrm{Pt}-\mathrm{Rh}$ and Pt-Ru [24-28]; the oxidation of metallic and alloy samples [29-31]; the adsorption and dissociation behaviors of different systems allowing the determination of kinetic parameters and energies of adsorption: $\mathrm{N}_{2}$ and $\mathrm{O}_{2} / \mathrm{Ni}-\mathrm{Cu}$ [32], $\mathrm{CO} / \mathrm{Mo}$, [33], S/Ni [34], cyanogen/Pt [35], $\mathrm{CO} / \mathrm{Ni}[36,37], \mathrm{NO}$ and $\mathrm{CO}+\mathrm{H}_{2} \mathrm{O} / \mathrm{Au}[38,39], \mathrm{CO}_{2} / \mathrm{Rh}$ [40], and methanol/Rh for applications in direct methanol fuel cells [41-43]. Reactive behaviors can be studied in detail, including CO oxidation on Rh [44-48]; methanation on Rh and Ir [49,50]; and NO hydrogenation on Pd and Au-Pd [51,52]. Furthermore, with 1DAP, it is possible to image reaction intermediates, such as oxide species during the $\mathrm{O}_{2}+\mathrm{H}_{2}$ reaction on $\mathrm{Rh}$ [53], the formation of $\mathrm{C}_{\mathrm{x}} \mathrm{H}_{\mathrm{y}}{ }^{+}$species during the Fischer-Tropsch reaction on cobalt catalysts [54,55], and even the early formation of carbon nanotubes on $\mathrm{Ni}[56,57]$.

More recent instruments, particularly the 3-dimensional atom probe (3DAP), are not intended to perform in situ analysis, but rather focus on the atomic-scale chemical analysis of both the surface and bulk of the sample through Atom Probe Tomography (APT) and three-dimensional reconstruction. These permit the study of post-facto oxidation/reduction behavior of the specimen, surface segregation in alloy systems, and behavior in the vicinity of structural defects. APT tip specimens can be qualified as 'model catalysts', bringing a valuable fundamental understanding of the catalytic systems, but are of limited value for more practical applications. With the new developments in the FIB-based sample preparation for APT, there is currently a growing interest in the analysis of 'real catalysts' (as compared to 'model catalysts') to highlight the presence of specific features such as core-shell structures, the homogeneity in the composition of nanoparticles, the distribution of elements within alloys, and aging effects.

After a brief description of the principles of APT, specimen preparation, and the latest developments of reaction cells for APT, this review will focus on the analysis of different catalytic systems by highlighting (i) the catalytic behavior and relevance of the studied materials, (ii) the specific specimen preparation used for APT studies, and (iii) the results of the APT analysis and the fundamental understanding they enable.

\section{Atom Probe Tomography}

\subsection{Atom Probe Tomography: Basic Principles}

Since its infancy in 1967 [58], atom probe tomography has become a well-established method for studying the 3D structure and composition of materials with high mass resolution, sub-nanometer spatial resolution and ppm elemental sensitivity [59-62]. APT is based on the phenomenon of field desorption, which consists of applying an electric field sufficiently high to desorb atoms from a surface [59-62]. By combining a static electric field with a pulsed electric field (or other pulsed energy source) and controlling the amplitude and frequency of the pulses, it is possible to field-evaporate a specimen, atom by atom, atomic layer by atomic layer, in a controlled fashion. A position-sensitive 
detector registers the position of impact of the ionized species (in $x$ and $y$ directions), and time-of-flight mass spectrometry (ToF-MS) is used to determine the chemical nature of the individual atoms. From the order of arrival of the desorbed species, $z$-axis information is recovered, and further data treatments allow the reconstruction of the three-dimensional structure of the initial specimen [63-67]. A schematic representation of the technique is depicted in Figure 1. APT is a destructive technique, performed under ultra-high vacuum (UHV) conditions, and the electric field required to desorb species varies with the chemical element and its close neighbors (typically in the $25-50 \mathrm{~V} \cdot \mathrm{nm}^{-1}$ range). Later advances greatly expanded the capabilities of the technique: the use of a local electrode to enhance the field effect (leading to the LEAP systems-Local Electrode Atom Probe), the use of a reflectron to increase the mass resolution, and the use of a pulsed laser to initiate evaporation permitting the study of non-conductive materials by APT [68-73]. In addition, advances in electronic components and computerization now allow collection of millions of atoms per hour as compared to a few hundred per day in the early years of the atom probe. Detailed experimental protocols to perform APT experiments and 3D reconstruction are widely available [59-67].

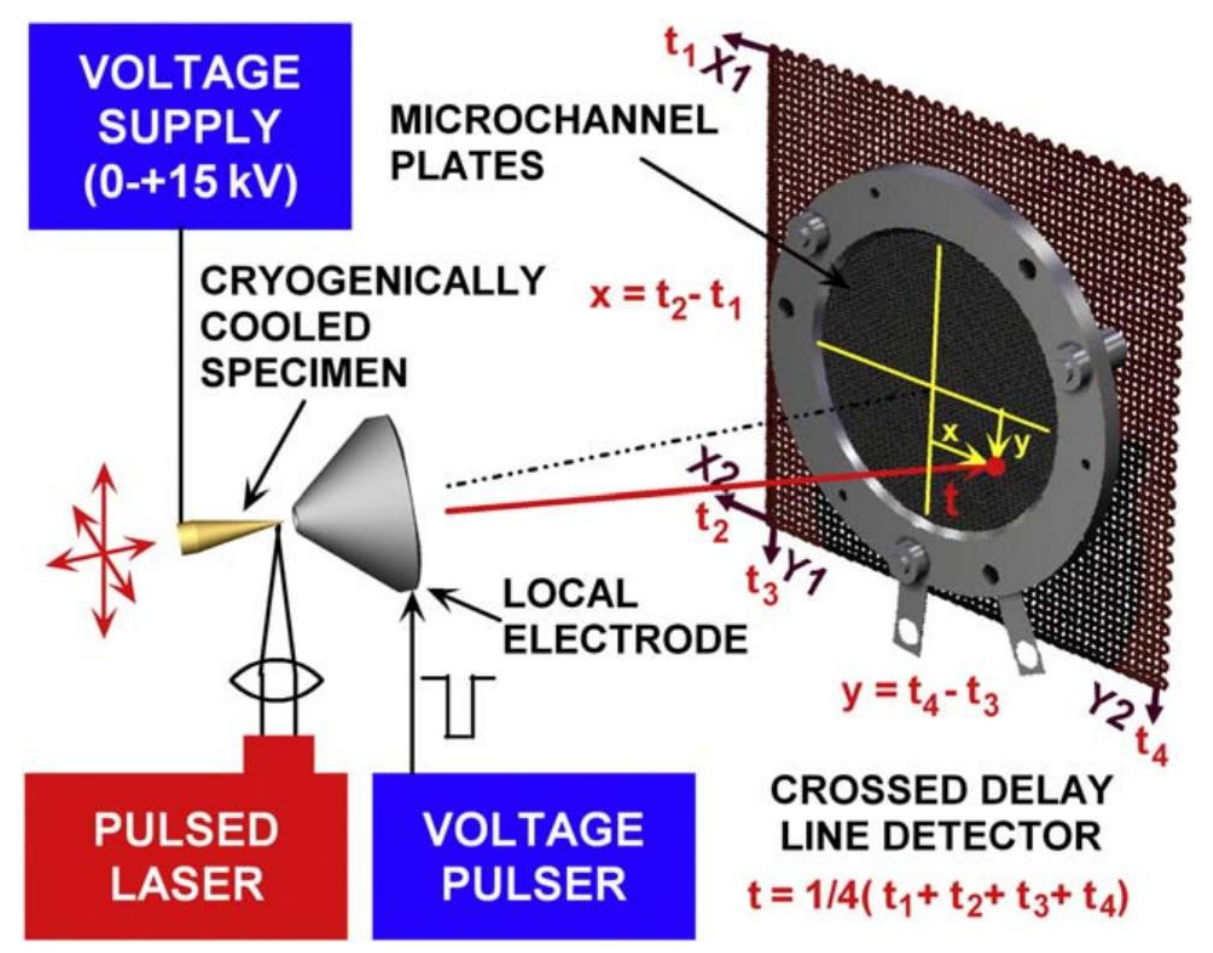

Figure 1. Schematic principle of the atom probe tomography with the specimen tip facing a position-sensitive detector. The evaporation of the specimen can be initiated by voltage or laser pulses. Reprinted from [74], Copyright (2009), with permission from Elsevier.

\subsection{Atom Probe Tomography: Specimen Preparation}

The high values of electric field, necessary to initiate and sustain the field evaporation process, are obtained by using field enhancement around highly curved surfaces. The specimens must therefore be prepared as sharp tips, with an apex diameter below $\approx 150 \mathrm{~nm}$. The two main methods used to obtain such sharp specimens are the electropolishing method, and focused ion beam (FIB) milling, which are described at length in the literature [58-62,75-79].

The electrochemical etching approach is used for conductive materials that can be prepared as wires, and is based on the controlled dissolution of the wire. Depending on the metal, different solutions can be used, either aqueous solutions (containing mostly $\mathrm{HClO}_{4}, \mathrm{H}_{2} \mathrm{CrO}_{4}, \mathrm{H}_{2} \mathrm{SO}_{4}, \mathrm{H}_{3} \mathrm{PO}_{4}$, $\mathrm{KCN}, \mathrm{HF}$ or $\mathrm{KOH}$ ) or molten salt mixtures for noble metals. At present, electropolishing is generally 
used to pre-sharpen tips, followed by micro-electropolishing at lower voltages while imaging by optical microscopy.

For samples that cannot be etched electrochemically, FIB-based methods constitute a powerful alternative using the lift-out procedure and ion milling. An example is given in Figure 2. From a bulk sample, a specific region of interest is selected, and a thin protective layer is deposited to minimize specimen damage during the sample preparation (Figure 2a). The regions surrounding the region of interest (ROI) are removed by ion milling, including an undercut below the sample, resulting in a rectangular lift-out bar that is still attached to the rest of the sample. A micromanipulator is then attached to the specimen by FIB-deposition of $\mathrm{Pt}$, and the lift-out bar cut free from the surrounding sample. The lift-out bar is transferred onto prefabricated micro-post (or carrier tips, or flat-top-post) by FIB-deposition and ion milling (Figure $2 b$ ); five to 10 specimens can be fabricated with a single lift-out bar. The last steps consist of sharpening the specimen by annular milling with decreasing annulus diameters to a final size suitable for APT analysis (Figure 2c-e). Alternatively, rectangular cuts and so-called "pyramid milling" can be used to decrease the annular milling time [79]. The final milling steps are performed at low kV to minimize Ga-ion implantation. With the FIB lift-out procedure, it is possible to select the orientation of analysis, allowing for damage-free specimen preparation [78], and also to perform site-specific specimen preparation [79,80]. Finally, the addition of correlative techniques further improves specimen preparation by targeting specific features that cannot be easily imaged by FIB-SEM (focused ion beam-scanning electron microscopy) [81-84].
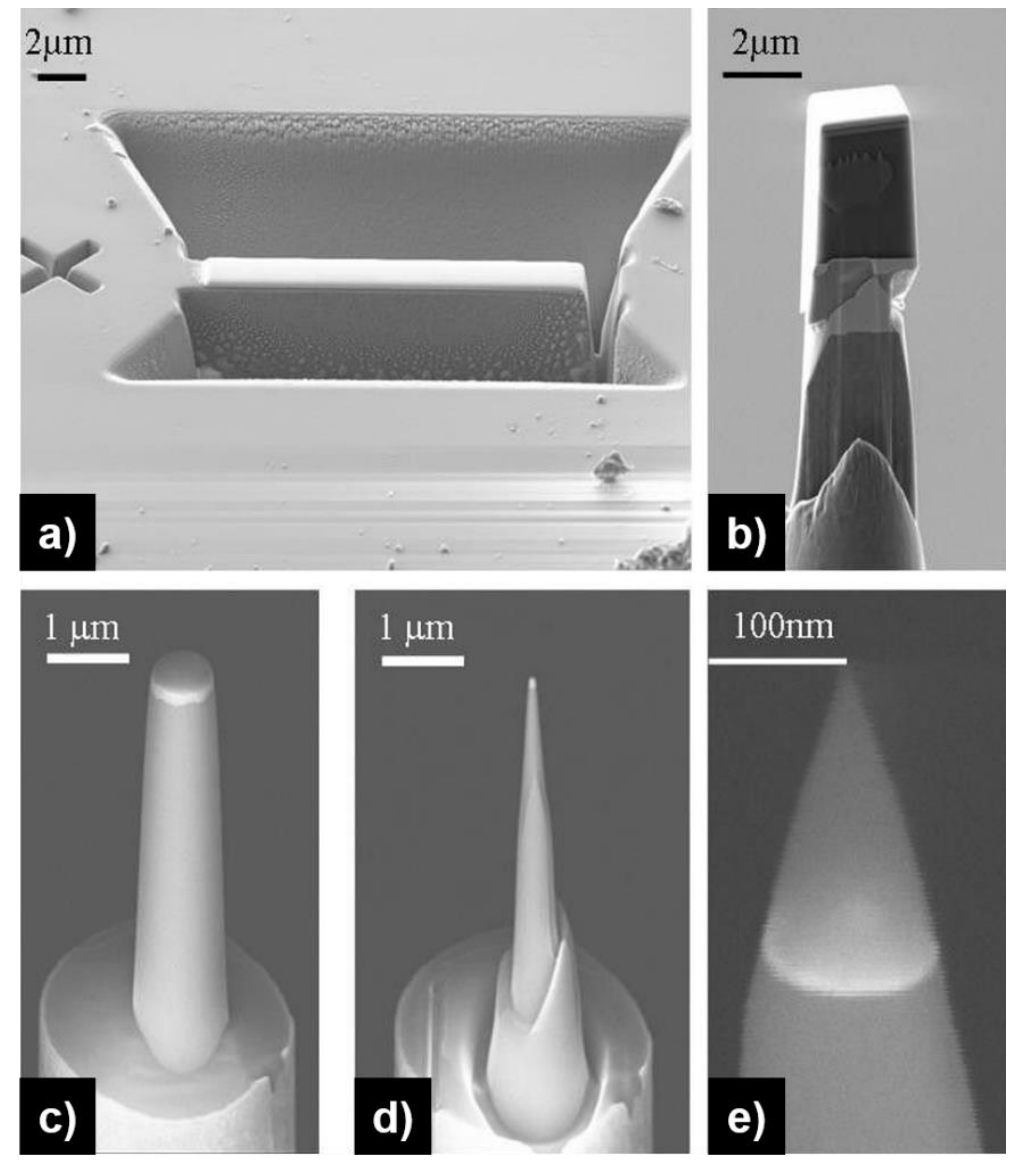

Figure 2. Procedure for Atom Probe Tomography (APT) specimen preparation by focused ion beam (FIB)-SEM: (a) lift-out method used to extract the lift-out bar made of the material of interest; (b) transfer of a portion of the bar onto a micro-post; (c-e) successive annular milling of decreasing size allow to obtain a sharp tip with a radius of curvature below $50 \mathrm{~nm}$. Reprinted from [77] under the terms of the Creative Commons Attribution License. 
Specific specimen preparation procedures have also been developed for the analysis of unsupported and supported nanoparticles, powders and porous materials; methods include electrophoresis, electrodeposition and encapsulation. These will be discussed on a case by case basis in Section 3 .

\subsection{Latest Developments: Environmental Cells for APT}

To extend the capabilities of APT, in situ reaction cells have been developed for catalysis applications and to study corrosion processes and aging. The role of these in situ reaction cells is to expose the specimen to different gaseous environments at high temperatures so as to mimic realistic reaction conditions, with the advantage of avoiding possible oxidation, surface contaminations and impurities from external sources due to the transfer between ex situ reaction cells and the APT. This is especially important for oxygen- and moisture-sensitive samples. The main requirements for such reaction cells are (1) ease of integration with existing instruments; (2) isolation of the specimen within an enclosed volume during gas exposure and heating treatments; and (3) the absence of interference with the regular operation of the APT. The general procedure consists of:

- $\quad$ cleaning the specimen by field evaporation (with regular APT analysis);

- $\quad$ transferring, under UHV conditions, the specimen to the reaction cell;

- $\quad$ isolating the cell from the rest of the instrument;

- $\quad$ applying reactive conditions (gases, $T$, time, ... );

- $\quad$ pumping the reaction cell;

- transferring, under UHV conditions, the specimen back to the analysis chamber.

Reactions cells designed for 3DAP systems can expose specimens to gas pressures up to 1 bar and at temperatures up to $873 \mathrm{~K}$ [85]; for modern versions of the instrument, cells exist with operating conditions of a few tens of mbar and up to $T \approx 723 \mathrm{~K}$ [86], and from $10^{-6}$ to $1000 \mathrm{mbar}$ and up to $T \approx 723 \mathrm{~K}$ with cryogenic quenching capabilities for the most recent design [87]. The improvement of APT analysis due to the use of in situ reaction cells is presented in Figure 3, corresponding to the analysis of $\mathrm{Al}$ oxidation under the same reaction conditions, but performed in ex situ (top spectra) and in situ (bottom spectra) cells [86]. Experiments performed in the ex situ cell reveal the presence of additional unassigned peaks in the mass spectra, probably originating in contamination during the transfer from the cell to the LEAP. This highlights the improvement over time in the instrument, as well as the reduction of the contamination with in situ cells.

Different systems have been studied with these cells: $\mathrm{NO}$ and $\mathrm{CO} / \mathrm{Pt}, \mathrm{NO}, \mathrm{CO}, \mathrm{O}_{2}, \mathrm{~N}_{2} \mathrm{O}, \mathrm{NO}+\mathrm{CO}$ and $\mathrm{NO}+\mathrm{O}_{2} / \mathrm{Pt}-\mathrm{Rh}[85,88,89], \mathrm{NO} / \mathrm{Pt}-\mathrm{Rh}-\mathrm{Ir}, \mathrm{NO} / \mathrm{Pt}-\mathrm{Rh}-\mathrm{Ru}[90], \mathrm{NO} / \mathrm{Au}-\mathrm{Pd}[52,91]$ and $\mathrm{O}_{2}, \mathrm{~N}_{2} \mathrm{O}$ and $\mathrm{H}_{2} / \mathrm{Au}-\mathrm{Ag}$ [92] for the 3DAP version of the cell; and $\mathrm{O}_{2} / \mathrm{Al}, \mathrm{O}_{2} / \mathrm{Pt}-\mathrm{Ir}, \mathrm{O}_{2} / \mathrm{Pt}-\mathrm{Rh}-\mathrm{Ir}$ [86]; $\mathrm{D}_{2} / \mathrm{Pd}, \mathrm{O}_{2}$ and $\mathrm{H}_{2} \mathrm{O} / \mathrm{Mg}$ [87] for the most recent cells.

Further developments are under way in the field of cryogenic transfer systems [93]. Indeed, the temperature and the gaseous environment control during transfer between instruments is mandatory for samples sensitive to air or thermal exposure, preventing chemical or morphological changes prior to analysis [94]. Environmental transfer hub and ultra-high vacuum carry transfer suitcase have been successfully used to improve the mass resolution of organometallic molecules analysis [94] and to investigate the surface oxidation of pure $\mathrm{Mg}$ during cryogenic transfer [95]. 

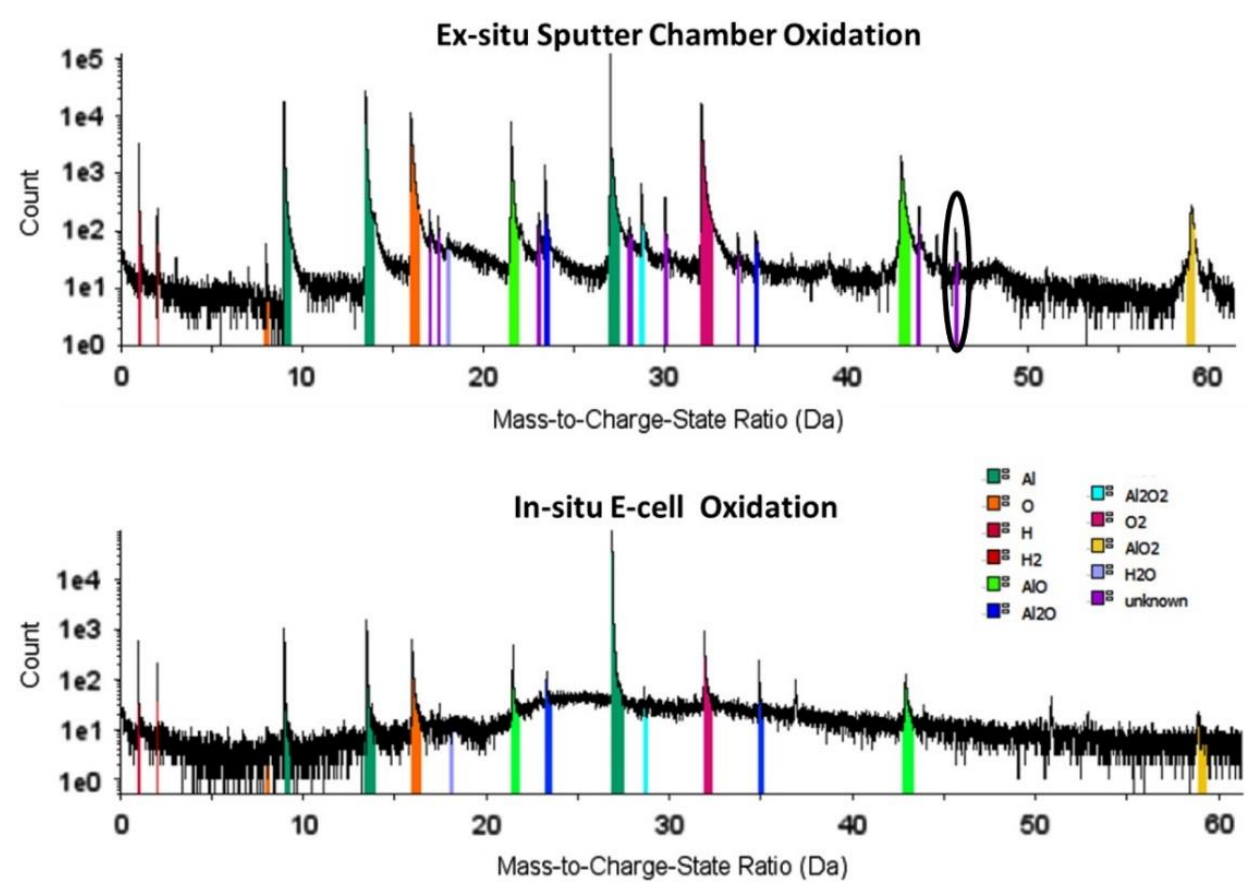

Figure 3. Mass spectra from APT analysis of Al oxidation performed under the same conditions but different reaction cells, ex situ (top spectra) and in situ (bottom spectra) cells, showing the lower contamination and higher resolution of the in situ environmental cell experiment. Reprinted from [86], Copyright (2014), with permission from Elsevier.

\section{Case Studies}

This section is dedicated to an in-depth analysis of catalytic systems studied by atom probe tomography and covers a rather wide range of catalytic materials of increasing complexity, from model tip-samples to zeolites. For tip-samples (Sections 3.1 and 3.2), the analysis of segregation behaviors occurring under different physico-chemical treatments is presented as an example of how APT results can inform the engineering of the surface composition of a catalyst. Section 3.3 focuses on the investigation of unsupported nanoparticles, with an emphasis on the sample preparation methods used to obtain suitable specimens for APT experiments, namely, the electrophoresis and the embedding methods. Section 3.4 describes oxide- and carbon-supported catalysts along with the inherent issues rising from the analysis of heterogeneous materials, and Section 3.5 discusses the analysis of catalysts in the form of powders. The study of porous catalysts in the form of self-supported nanoporous materials is addressed in Section 3.6, with an emphasis on sample preparation and influence of the composition on the morphology. A particular class of porous materials known as zeolites is presented in Section 3.7 with APT being used to unravel the location of elements, modifications to the material's structure, and deactivation processes.

\subsection{Model Catalysts as Tips-Focus on the Surface}

This section focusses on the analysis of model catalytic systems using tip-samples, the extremity of which mimics a single nanoparticle of catalyst, with experiments performed by FEM, FIM and 1DAP, all of these methods are sensitive to the near surface region (a few tens of atomic layers in depth). The studies presented here describe the presence of different segregation behaviors due to physico-chemical treatments of Pt-based and Au-based alloys. Understanding the surface segregation behaviors of catalytic materials is vital since the synergistic effects between different metals depend on their surface concentration ratios. Furthermore, the design of catalysts with specific properties requires a control of the segregation behaviors under reaction conditions since those processes lead to deviations from the bulk composition and may affect the catalytic activity and/or selectivity of the materials. 


\subsubsection{Pt-Based Alloys}

Pt-based catalysts are used for various applications, among which the most important is the treatment of automobile exhaust gases, due to their low oxidation properties and stability at high temperatures [96]. A better understanding of the dynamic behaviors of alloys is required to fine-tune the surface composition of the catalyst, and improve its efficiency towards NOx reduction, CO oxidation and hydrocarbon oxidation. Different Pt-based alloys have been studied with a focus on the near surface, i.e., the very first atomic layers, with FIM methods allowing for a facet-specific analysis rather than a global analysis of the model nanoparticle.

Pt-Rh samples, with a composition of Pt-17.4 at.\% Rh, were studied after exposure to pure gases, mixtures of gases (either simultaneous or sequential exposure) and at different temperatures to understand the segregation behaviors. The specimens were produced by the electropolishing method from a Pt-17.4 at.\% Rh wire in a molten salt mixture of $4: 1 \mathrm{NaNO}_{3}: \mathrm{NaCl}(\mathrm{w}: \mathrm{w})$ at $\approx 520{ }^{\circ} \mathrm{C}$. After pre-characterization, the specimens were exposed to different gases under field-free conditions to avoid any field-induced effects (field-induced morphological changes, field-induced dissociation ... [97]). Segregation behaviors can be analyzed layer-by-layer and quantitatively using 'temperature-concentration plots'. Different segregation behaviors have been observed: for example, a Rh enrichment layer at the surface followed by a Rh depleted layer, Rh depletion at the surface, or even an enrichment layer turning into a depletion layer at a given temperature. The results $[85,88,89]$ obtained on this Pt-Rh alloy can be summarized as follows:

- the surface segregation behavior is facet-dependent due to different surface free energies and different diffusion processes;

- the surface segregation behavior is temperature-dependent, allowing observation of Rh surface segregation below a threshold temperature, and Rh surface depletion above this temperature;

- $\quad$ some oxygen-bearing molecules $\left(\mathrm{NO}, \mathrm{O}_{2}\right.$ and $\mathrm{N}_{2} \mathrm{O}$ ) cause surface segregation, whereas $\mathrm{CO}$ induces very little segregation, suggesting that the presence of atomic oxygen drives surface segregation in Pt-Rh;

- the competitive segregation effects due to different surface properties can be studied by exposing the specimen to different gases simultaneously or one after another, for example CO preventing the build-up of oxide layer and limiting the extent of segregation.

A careful analysis shows that in some cases, the extent of the Rh enriched layer is not compensated by the Rh depleted region, signifying that multiple different diffusion processes are present. Vertical diffusion can occur, from the bulk to the surface, but so can lateral diffusion, from one facet to the other. In the case of Pt-Rh exposure to NO, lateral diffusion occurs from $\{001\},\{011\},\{012\}$ towards $\{111\}$ facets where the oxide-species are the most stable. This was later simulated by a model considering the transport processes normal and parallel to the surface [98].

The results obtained on Pt-17.4 at.\% Rh were compared to experiments on Pt-23.9 at.\% Rh-9.6 at.\% Ru and Pt-17.3 at.\% Rh-14.0 at.\% Ir specimens [90], also produced with the same electropolishing methodology. Adding a third element to Pt-Rh catalysts improves the activity towards specific reactions, increases the resistance to poisoning or decreases the light-off temperature. On Pt-Rh-Ru alloys, the presence of Ru stabilizes the $\{111\}$ surface since no segregation can be observed after exposure at increasing temperatures, even after longer exposures $(1 \mathrm{~h})$. On the $\{001\}$ facet, Rh behavior is similar to the Pt-Rh case, i.e., surface segregation and surface depletion above a threshold temperature, but to a lower extent. The Ru species are unstable above $423 \mathrm{~K}$. On Pt-Rh-Ir alloys, the $\{111\}$ surface becomes Rh and Ir enriched with increasing temperature during NO exposure, similar to the Pt-Rh case; whereas on the $\{001\}$, Rh-species appear stabilized to a higher temperature.

It can be concluded that single-gas APT experiments can improve the understanding of the effects of gaseous mixtures on heterogeneous catalyst surfaces. Moreover, the surface composition depends on the exact atomic ratio of elements in the alloy, on the surface crystallography, and on the temperature of exposure, highlighting the importance of such studies for better engineering of catalysts. 


\subsubsection{Au-Based Alloys}

Au-based catalysts are commonly used for deNOx applications [99-101], and in this frame, two types of catalysts have been studied by APT: Pd-Au and Au-Ag.

Adsorbate-Induced Segregation on Pd-Au

Pd-Au specimens, with a composition of Pd-38 at.\% Au, were studied after NO gas exposure at different temperatures and $60 \mathrm{mbar}[52,91,102]$. The sample preparation was performed using the electropolishing method from a Pd-38 at. $\%$ Au wire, using an aqueous solution of $20 \% \mathrm{KCN}$ with $3 \mathrm{~V}_{\mathrm{DC}}$. When the Pd-Au specimen undergoes thermal treatment up to $573 \mathrm{~K}$ under vacuum conditions, we can observe a homogeneous distribution of $\mathrm{Pd}$ and $\mathrm{Au}$, showing no segregation. However, exposing the same specimen to $\mathrm{NO}$ at $573 \mathrm{~K}$ for $15 \mathrm{~min}$ leads to Pd surface segregation: the initial sample composition of Pd-38 at.\% Au becomes Pd-20 at.\% Au. Further 1DAP experiments demonstrated the dissociation of $\mathrm{NO}$ on similar specimens, and the segregation behavior can thus be explained by the occurrence of NO dissociation on $\mathrm{Pd}-\mathrm{Au}$, with the formation of strong $\mathrm{Pd}-\mathrm{O}$ bonds as compared to $\mathrm{Au}-\mathrm{O}$ bonds at the surface [103]. This, then, is an adsorbate-induced segregation which is thermodynamically driven. Finally, exposing the same specimen to $\mathrm{NO}$ at $300 \mathrm{~K}$ for $15 \mathrm{~min}$ did not induce any segregation/depletion phenomena, confirming that the segregation is thermally activated.

\section{Bulk Diffusion vs. Surface Diffusion on Au-Ag}

More recently, $\mathrm{Au}-\mathrm{Ag}$ materials have been used as bifunctional catalysts: the minor $\mathrm{Ag}$ is active for oxygen dissociation and $\mathrm{Au}$ guides selectivity. $\mathrm{Au}-\mathrm{Ag}$ materials are efficient catalysts for selective oxidation reactions [104-107], but there is a lack of understanding of the activation processes leading to such efficiency. In this context, simple molecules are used to study the reaction dynamics [108] and the segregation processes [92] by field emission techniques.

In particular, $\mathrm{Au}-\mathrm{Ag}$ specimens [92], with a composition of $\mathrm{Au}-8.8$ at. $\% \mathrm{Ag}$, were studied after $\mathrm{O}_{2}$, $\mathrm{N}_{2} \mathrm{O}$ and $\mathrm{H}_{2}$ gas exposure at different temperatures and 60 mbar pressure. The sample preparation was performed using the electropolishing method from a Au-8.8 at.\% Ag wire, using an aqueous solution of $20 \% \mathrm{KCN}$ with $2-4 \mathrm{~V}_{\mathrm{DC}}$. Similar to the previous Pd-Au case, thermal treatments for $1 \mathrm{~h}$ and at temperatures up to $573 \mathrm{~K}$ under vacuum conditions did not lead to any segregation behavior, in agreement with the estimation of Ag diffusion length. However, longer thermal treatments of $17 \mathrm{~h}$ at 373,473 and $573 \mathrm{~K}$ lead to the observation of segregation extending over four to eight atomic layers. This suggests that, if given sufficient time for the diffusion to occur, Ag will preferentially segregate to the surface, which is explained by the lower free surface energy and lower molar heat of sublimation of Ag as compared to $\mathrm{Au}[109,110]$. When the specimen is exposed to oxidative gases, a different $\mathrm{Ag}$ surface segregation occurs (see Figure 4). In the first case, $\mathrm{O}_{2}$ induces a substantial surface segregation in terms of Au to Ag ratio, with surface concentration up to 99.2 at.\% Ag after $1 \mathrm{~h}$ of treatment at temperatures as low as $323 \mathrm{~K}$. In the second case, $\mathrm{N}_{2} \mathrm{O}$ exposure also induces Ag segregation, but to a lower extent, with a maximum of 41.8 at.\% Ag after $1 \mathrm{~h}$ of treatment at temperatures starting from $373 \mathrm{~K}$. As expected, $17 \mathrm{~h}$ of treatments leads to greater segregation behavior. Figure 4 represents the cumulative fraction diagram and the $3 \mathrm{D}$ reconstruction of the $\mathrm{O}_{2}$ and $\mathrm{N}_{2} \mathrm{O}$ experiments. The cumulative fraction diagram plots the total number of $\mathrm{Au}$ and $\mathrm{Ag}$ atoms detected as a function of the total number of $\mathrm{Ag}$ atoms detected. The slope of such plots corresponds to the composition of the analyzed specimen, and any changes indicate segregation or depletion behavior. In the $\mathrm{O}_{2}$ case (Figure 4a,b), Ag segregation is observed at the surface, followed by the nominal composition of the bulk. However, in the $\mathrm{N}_{2} \mathrm{O}$ case (Figure 4c,d), the Ag segregation region (41.8 at.\% $\mathrm{Ag}$ ) is directly followed by a depletion region (4.5 at.\% Ag), and then the nominal composition of the bulk is recovered. The segregation behaviors are due to surface diffusion after $\mathrm{O}_{2}$ exposure, and to bulk diffusion after $\mathrm{N}_{2} \mathrm{O}$ exposure: it is suggested that the different dissociation properties of these gases explain this difference. Finally, early results on the possible Au surface segregation have been 
reported, exposing the specimen to reducing atmosphere ( $\mathrm{H}_{2}$ exposure) at 323 and $373 \mathrm{~K}$ for $1 \mathrm{~h}$, which is likely to be due to field-induced surface diffusion of gold during the analysis.

(a)

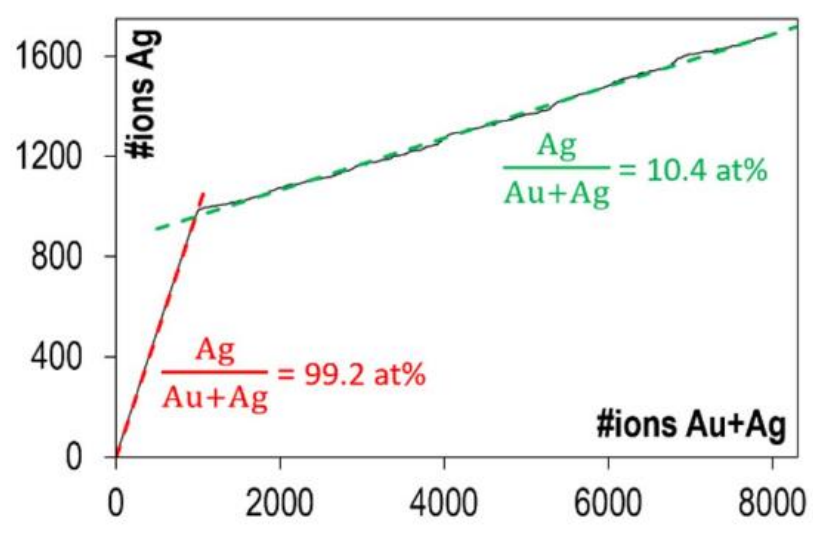

(c)

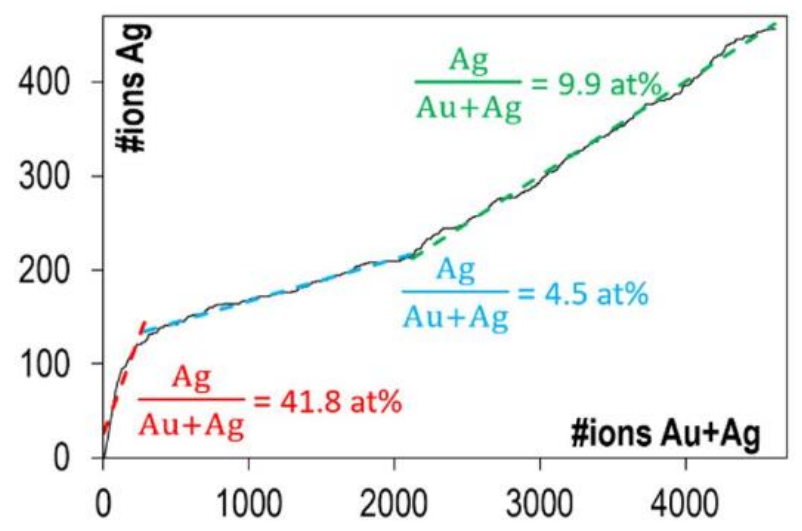

(b)

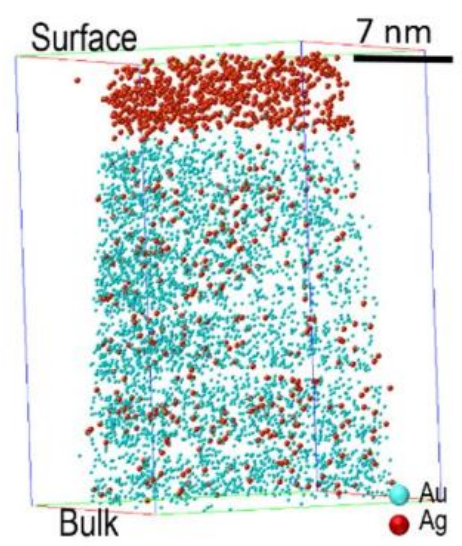

(d)

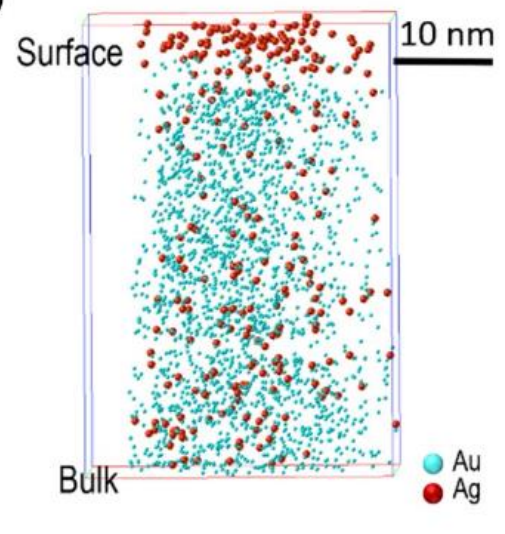

Figure 4. Different segregation behaviors in Au-Ag tip-samples: (a) cumulative fraction diagram and (b) $3 \mathrm{D}$ reconstruction of $\mathrm{O}_{2}$-treated $\mathrm{Au}$-Ag specimen ( $1 \mathrm{~h}$ at $373 \mathrm{~K}$ ) showing Ag surface segregation (99.2 at.\%) due to surface diffusion; (c) cumulative fraction diagram and (d) 3D reconstruction of $\mathrm{N}_{2} \mathrm{O}$-treated $\mathrm{Au}-\mathrm{Ag}$ specimen $(0.5 \mathrm{~h}$ at $423 \mathrm{~K})$ showing a $\mathrm{Ag}$ segregation region (41.8 at.\%) tailed by a Ag depletion region (4.5 at.\%) before recovering the initial bulk concentration due to bulk diffusion. Reprinted by permission from Springer: [92], Copyright (2018).

Experiments on both $\mathrm{Pd}-\mathrm{Au}$ and $\mathrm{Au}-\mathrm{Ag}$ further show that the composition of the surface can be fine-tuned by applying different physico-chemical treatments and by controlling the gaseous environment, the temperature and the length of the treatment.

\subsection{Model Catalysts as Tips-Focus on the Surface and Bulk}

Using tip-samples as model catalysts, this section addresses the global behavior of Pt-based catalysts, concentrating on both the surface and the bulk rather than on a facet-to-facet analysis as was the case in Section 3.1. This research is driven by the challenge of minimizing the amount of expensive platinum group metals used as catalysts, without affecting the catalytic activity. One option is the design of nano-engineered catalysts for which a thorough atomic scale understanding of the catalytic materials is required.

\subsubsection{Engineering the Surface Composition of Pt-Based Alloys}

The first example consists of Pt-22 at.\% Rh samples which were prepared using the electropolishing method in a molten salt mixture. Those specimens were then oxidized under oxygen flow to study the 
formation of oxides [111]. The investigation shows that the oxide phase nucleates from the surface and then grows inwards. The concentration profiles not only reveal the stoichiometry of the oxide, $\mathrm{M}_{2} \mathrm{O}_{3}$ $(\mathrm{M}=\mathrm{Rh}+\mathrm{Pt})$, but can also distinguish different regions: a Rh-enriched oxide-phase (composition: with 35 to 40 at.\% of Rh as compared to the initial 22 at.\%), a Rh-depleted region; and the bulk with the nominal concentration. Using increasing oxidation temperatures $(873,973$ and $1073 \mathrm{~K})$ the kinetics of oxide growth can be studied, including the activation energy for Rh diffusion, and the diffusion coefficients at different temperatures can be measured. In this case, the diffusion of Rh from the bulk to the oxide/metal interface is the rate-limiting step in the oxide growth. Applying an oxidation/reduction cycle produces a thin layer of almost pure $\mathrm{Rh}$ at the surface (composition: $99.6 \pm 1.3$ at.\% Rh- $0.4 \pm 0.1$ at. $\%$ Pt), leading to a core-shell structure (Figure $5 \mathrm{a}$ ) with a shell made of the most active and expensive metal.

Similar oxidation and oxidation/reduction experiments were performed on Pd-6.4 at.\% Rh samples [112]. The specimens were prepared by the electropolishing method in $10 \%$ perchloric acid and $90 \%$ acetic acid, followed by $2 \%$ perchloric acid and $98 \%$ butoxyethanol during a second electropolishing stage. Early stages of oxidation at $873 \mathrm{~K}$ lead to the formation of an oxide layer with PdO stoichiometry (composition: $46.6 \pm 0.2$ at. $\%$ Pd- $2.7 \pm 0.1$ at. $\%$ Rh- $50.7 \pm 0.2$ at. $\%$ O). As oxidation time increases, the oxide layer evolves towards different isolated phases: Pd-oxide (PdO stoichiometry), Pd-Rh mixed oxide $\left(\left(\mathrm{Rh}_{1} \mathrm{Pd}_{1}\right) \mathrm{O}_{2}\right.$ stoichiometry) and $\mathrm{Pd}$-rich suboxide $\left(\mathrm{Pd}_{2} \mathrm{O}\right.$ stoichiometry). Reduction in hydrogen efficiently removes the oxygen but does not significantly affect the distribution of metallic species. The isolated phases—or islands-are thus preserved leading to the formation of distinct Pd-rich and Rh-rich (composition: $54.1 \pm 2.0$ at.\% Rh-45.9 \pm 1.8 at.\% Pd) clusters (Figure $5 b$ ). This provides a convenient way to synthesize multifunctional catalysts with nanoscale regions of differing composition in close proximity.

a)

b)<smiles>[Rh][Pb]</smiles>

c)

d)

e)

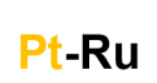

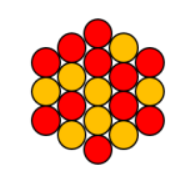
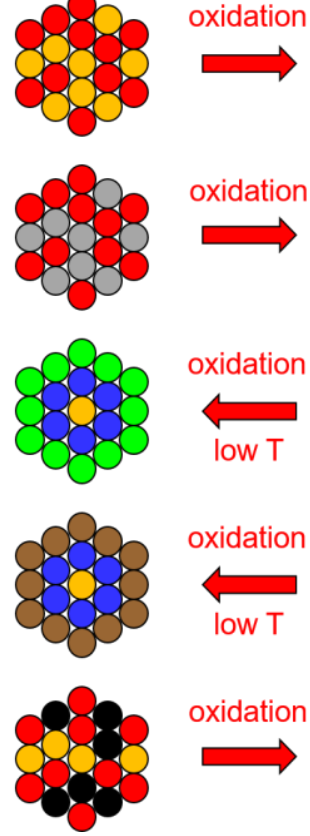

oxidation

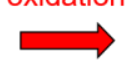

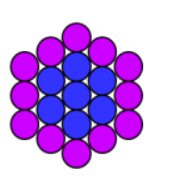
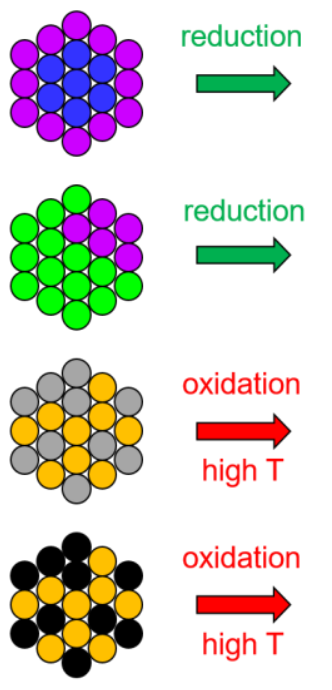

reduction

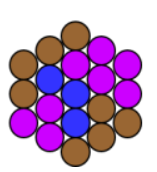

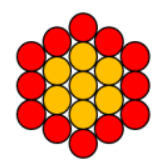
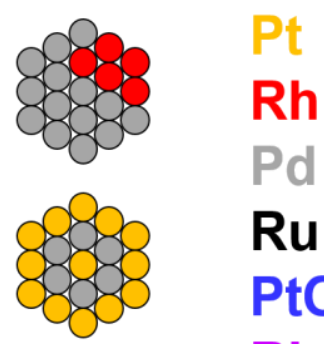

\section{Ru}

$\mathrm{PtO}_{\mathrm{x}}$
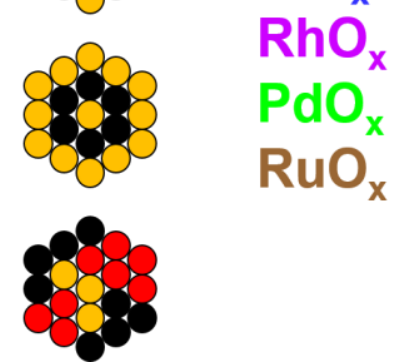

Figure 5. Schematic representation of different behaviors observed upon oxidation and oxidation/reduction cycles allowing for a better engineering of nanoparticles. (a) Core-shell formation in the Pt-Rh system; (b) phase separation into nanoregions in the Pd-Rd system; (c) switch between $\mathrm{Pt}$ and Pd enrichment as a function of the temperature in Pt-Pd system; (d) switch between Pt and $\mathrm{Ru}$ enrichment as a function of the temperature in Pt-Ru system; and (e) phase separation in the Pt-Rh-Ru system. Adapted from [113], Copyright (2013), with permission from Elsevier and adapted with permission from [114]. Copyright (2012) American Chemical Society. 
A third set of experiments was performed on Pt-Pd alloy [113]. Pt-31 at.\% Pd specimens were produced with the same electropolishing method as Pt-Rh specimens, and then oxidized for $5 \mathrm{~h}$ under 1 bar of oxygen flow at 673, 773, 873, 973 and $1073 \mathrm{~K}$. Three different oxidation regimes were observed. At $673-773 \mathrm{~K}$, a Pd-rich thin oxide is formed at the surface, which evolves into a thick PdO oxide layer at $873 \mathrm{~K}$. Beneath the $\mathrm{PdO}$ layer, a Pd-depleted region is present with an interfacial $\mathrm{PtO}_{\mathrm{x}}$ layer. Finally, above $973 \mathrm{~K}$, the surface became metallic and Pt-rich. To understand this behavior, the heat of formation of Pt- and Pd-oxides, the formation of volatile oxides and kinetic effects of oxides evaporation was considered. Solid oxide phases are absent, presumably due to volatility, leading to a surface enriched in Pt. This system highlights that oxidation treatment at different temperatures allows tuning of the surface composition of Pt-Pd to be either Pt-rich or Pd-rich, forming two different types of core-shell structures (Figure 5c). Along with Pt-Rh and Pd-Rh, the Pt-Pd example shows a third way of engineering the surface of catalytic materials and highlights the fact that similar conditions can lead to dramatic differences in oxidation behavior.

Finally, the oxidation and oxidation/reduction behavior of $\mathrm{Pt}-\mathrm{Ru}$ and $\mathrm{Pt}-\mathrm{Rh}-\mathrm{Ru}$ samples has been investigated [114]. Pt-8.9 at.\% Ru and Pt-23.9 at.\% Rh-9.7 at.\% Ru specimens have been produced with the same electropolishing method as Pt-Rh specimens. The oxidation of Pt-Ru specimens at 773 and $873 \mathrm{~K}$ leads to $\mathrm{Ru}$-enriched surfaces with a $\mathrm{Ru} /(\mathrm{Ru}+\mathrm{Pt})$ ratio of $22 \%$ instead of the initial $8.9 \%$. Beneath this Ru-enriched region is a Ru-depleted region, suggesting bulk diffusion. Inversely, at $973 \mathrm{~K}$, the surface is enriched in Pt with only traces of $\mathrm{Ru}$ (composition: $99.6 \pm 0.3$ at. $\%$ of $\mathrm{Pt}$ and $0.4 \pm 0.08$ at. $\%$ of $\mathrm{Ru}$ ). However, the Ru-depleted region is still present and greater than at lower oxidations temperature, suggesting the volatilization of the Ru species during oxidation. This is not surprising, as $\mathrm{Pt}$ and $\mathrm{Ru}$ oxides are not stable at high temperatures, and the rate of Ru volatilization is known to be higher. Therefore, from a homogeneous $\mathrm{Pt}-\mathrm{Ru}$ sample, it is possible to generate a Ru-rich or a $\mathrm{Pt}$-rich (Pt-rich(shell)-Pt/Ru(core) structure to be exact) surface as a function of the temperature of oxidation (Figure 5d), as in the Pt-Pd case. On the Pt-Rh-Ru samples, the oxidation initiates at grain boundary regions with a $\mathrm{MO}_{2}$ stoichiometry. Further oxidation leads to separate Rh-rich (stoichiometry: $\left.(\mathrm{Rh}, \mathrm{Ru})_{2} \mathrm{O}_{3}\right)$ and Ru-rich (stoichiometry: $\left.(\mathrm{Ru}, \mathrm{Rh}) \mathrm{O}_{2}\right)$ oxide phases, the structure of which is retained upon reduction in hydrogen at low temperature, leading to isolated phases as in the Pd-Rh case (Figure 5e).

Analysis of Pt-10.1 at.\% Ir [86] using a reaction cell leads to Ir enrichment upon oxidation, as well as competitive Ir and Rh surface segregation in the Pt-17.3 at.\% Rh-14.0 at.\% Ir alloy, consistent with previous experiments focusing on $\{111\}$ and $\{001\}$ facets only [90].

\subsubsection{Region-Specific Analysis of Pt-Based Catalysts}

One phenomenon of interest is the catalytic activity of Pt-Pd alloys when exposed to $\mathrm{C}_{x} \mathrm{H}_{\mathrm{y}}$ films. Pt-20 at.\% Pd specimens were prepared by the electropolishing method using an aqueous solution of $20 \% \mathrm{CaCl}_{2}$ and $35 \mathrm{~V}_{\mathrm{AC}}$, followed by a FIB milling. A thin layer $(<10 \mathrm{~nm})$ of $\mathrm{C}_{\mathrm{x}} \mathrm{H}_{\mathrm{y}}$ was deposited on the surface by e-beam deposition of phenantrene, and then heated by laser irradiation for $2 \mathrm{~h}$. Untreated $\mathrm{Pt}-\mathrm{Pd}$ specimens reveal a uniform concentration profile, however, on thermally treated specimens $\mathrm{Pd}$ segregation occurs as Pd-oxides species. An interesting point is that after heating at $873 \mathrm{~K}$, the APT analysis of the phenantrene-covered specimen returns different mass spectra at the surface of the $\mathrm{C}_{x} \mathrm{H}_{\mathrm{y}}$ thin films and at the interface of the $\mathrm{Pt}-\mathrm{Pd} / \mathrm{C}_{\mathrm{x}} \mathrm{H}_{\mathrm{y}}$, suggesting that a catalytic reaction occurred [115], although the details are uncertain.

A correlative SEM, FIB, EDX (Energy-Dispersive X-ray spectroscopy), thermogravimetry and APT study was performed on Pt-Rh-Pd gauze catalyst (composition 83 at.\% Pt-8 at.\% Pd-9 at.\% Rh) [116]. Samples for APT analysis were produced using the electropolishing method for control experiments; and using the FIB lift-out method for specific areas: near a grain boundary and at the center of the grain. After $5 \mathrm{~h}$ of oxidation under oxygen flow and at temperatures from 873 to $1273 \mathrm{~K}$, the results highlight different segregation behaviors as a function of the region analyzed. At the grain boundary, an oxide layer is formed consisting mainly of $\mathrm{Rh}_{2} \mathrm{O}_{3}$ species, with only traces of Pt-oxides. Below this 
oxide layer, the specimen is Rh depleted (with a concentration of 0.4 at.\%). Further away from the grain boundary, a Pd enrichment forming a 1-2 nm layer (reaching 20-35 at.\% of Pd) and a slight $\mathrm{Rh}$ enrichment (12-18 at.\%) can be observed. This indicates that the Rh oxide is the most likely oxide to form, preferentially at the grain boundaries, and that Pd does not play a significant role in the oxidation at grain boundaries. After analyzing different regions of the same specimen by APT with site-specific lift-out, a more complete picture of the catalyst's structure and composition was obtained. This highlights one of the limitations encountered when using a tip-sample produced from a wire to mimic the behavior of a real catalyst. The next sections will focus on the investigations of real catalysts by atom probe tomography.

\subsection{Catalysts as Unsupported Nanoparticles}

Performing APT experiments on real-world catalysts remains challenging. There is a broad diversity of catalysts' structures, sizes and morphologies, and thus there is no generic recipe for their preparation. Every sample is different, and a specific sample preparation needs to be developed for every category of sample: supported nanoparticles, unsupported nanoparticles, porous materials such as zeolites, nanoporous materials or agglomeration of catalysts as powders. From an APT point of view, the sample preparation should be optimized to reduce as much as possible the presence of aberrations during the analysis and 3D reconstruction: this can be done by avoiding the presence of high (or low) field precipitates if an embedding method is chosen, and by avoiding the presence of surface heterogeneities leading to enhanced local electric fields. From a catalyst point of view, the sample preparation has to preserve the integrity of the sample and should thus avoid the use of processes inducing chemical or structural changes of the catalysts; for example, oxidation/reduction processes, reaction of the catalytic materials with the embedding medium, or sample preparation requiring a high temperature (relative to the structural stability of the sample). The following examples present two different sample preparation methods applied to the analysis of unsupported nanoparticles: the electrophoresis method and embedding method.

\subsubsection{Imaging Core-Shell Ag@Pd Nanoparticles-Electrophoresis Method}

Hydrogen is an important energy vector in fuel cell technology, but the storage of pure hydrogen remains an issue [117]. To overcome this problem, one of the possibilities is to use stored hydrogen in the form of a liquid organic compound, which can then be released in situ, at low temperature and without the production of contaminants, such as $\mathrm{CO}$, to avoid a loss of the fuel cell's efficiency. The decomposition of formic acid can lead to the release of hydrogen and has been used in liquid-phase transfer hydrogenation reactions [118]. However, the nature of the catalyst and the operating temperature are important parameters, and there is an absence of active and selective solid catalysts for formic acid decomposition at room temperature. The literature reports $\mathrm{Pd}$ as the most active metal for formic acid decomposition in aqueous phase [119], and the authors found that the activity is closely linked to the electronic properties of metallic nanoparticles, following the trend $\mathrm{Pd}>\mathrm{Rh}>\mathrm{Pt} \approx \mathrm{Ru}>$ $\mathrm{Au}>\mathrm{Ag}$ [120]. To further improve the catalytic process in terms of activity and cost, the synthesis of core-shell structures is a common strategy. Charge transfer between core and shell is known to modify the chemical properties of the surface. Pd-shell bimetallic nanoparticles with $\mathrm{Ru}, \mathrm{Rh}, \mathrm{Pt}, \mathrm{Ag}$ or $\mathrm{Au}$ core have been synthesized, and it has been shown that Ag@Pd nanoparticles are the most active catalyst for formic acid decomposition at $20^{\circ} \mathrm{C}$. A more detailed analysis reveals that the thinnest Pd shell (with a 1:1 Ag:Pd ratio) is more active than thicker Pd shells (1:2 and 1:3 ratios). To confirm this, however, nanoscale characterization was necessary, so APT was used to characterize Ag@Pd nanoparticles with $1: 1$ and $1: 3$ ratios.

The specimens were prepared using the electrophoresis method. The basic principle consists of depositing a droplet of the nanoparticles in solution on an electropolishing loop. Then, a voltage bias is applied between the loop and a Pt or Pt-Rh tip-sample, causing the nanoparticles to deposit on the tip-sample by electrophoresis (Figure 6a). The efficiency of the process depends on the nanoparticles 
size, size distribution and polarity, on the voltage applied and its duration, and on the tip size. A typical value used in this work is $5-15 \mathrm{~V}_{\mathrm{DC}}$ for $10 \mathrm{~s}$. Longer exposure leads to agglomeration of nanoparticles. The deposition is checked by electron microscopy (Figure $6 \mathrm{~b}, \mathrm{c}$ ) prior to introduction in the APT instrument.

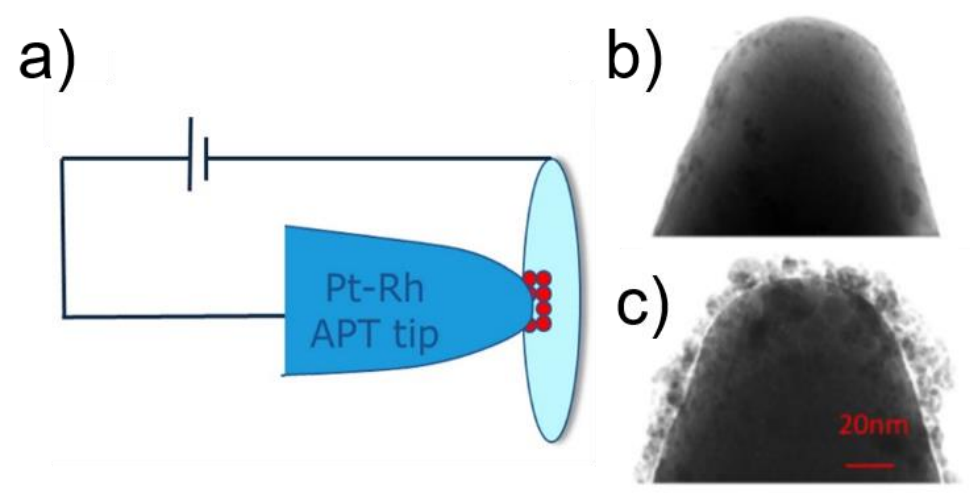

Figure 6. Sample preparation by electrophoresis. (a) Schematic principle of the deposition method; (b) Transmission Electron Microscopy (TEM) image of a Pt specimen before deposition and; (c) TEM image of the same Pt specimen after deposition of Ag@Pd nanoparticles. Panel (a): Reprinted with permission from [121]. Copyright (2014) American Chemical Society. Panels (b,c): Reprinted by permission from Nature: [120], Copyright (2011).

APT measurement of 1:1 Ag@Pd nanoparticles is presented Figure 7. The atom map Figure 7a depicts Ag atoms as grey balls and Pd atoms as yellow balls: two distinct nanoparticles can be clearly distinguished using the isosurface method. A localized reconstruction of one of the particles is represented Figure $7 \mathrm{~b}, \mathrm{c}$ and shows a core-shell structure with a core almost entirely made of $\mathrm{Ag}$, a shell rich in Pd extending over one to two atomic layers, and a sharp interface of less than $0.5 \mathrm{~nm}$ in width. Similar data reconstruction on the 1:3 ratio indicates a Pd shell five to 10 atomic layers thick. Correlating the catalytic activity with the nanoscale characterization suggest that the electronic promotion of $\mathrm{Pd}$ by the core $\mathrm{Ag}$ has a short range of just a few atomic distances. This electronic promotion leads to enhanced catalytic properties, proving the importance of nanoparticle engineering to obtain the optimum catalysts for the decomposition of formic acid.
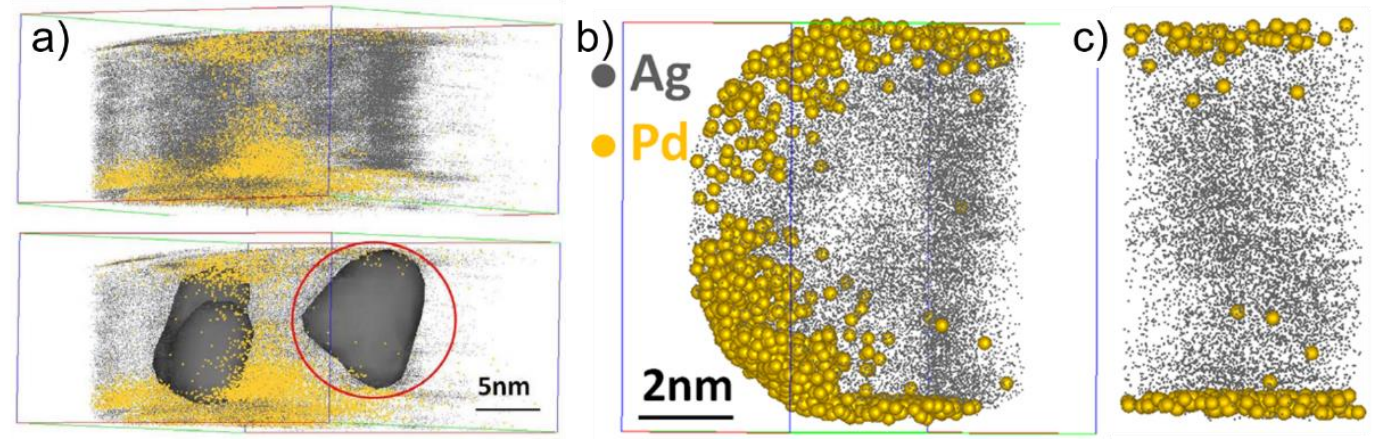

Figure 7. Analysis of Ag@Pd nanoparticles prepared by the electrophoresis method. (a) Atom map of Ag@Pd nanoparticles with 1:1 ratio showing two distinct particles (highlighted by applying the isosurface method in the bottom part); (b) local reconstruction of one single particle; and (c) slice through an individual nanoparticle showing the presence of a Ag core and a one to two atomic layer Pd shell. Reprinted by permission from Nature: [120], Copyright (2011).

A similar electrophoresis method was used to study the structure and composition of $\mathrm{CuZnGaO}_{\mathrm{x}}$ catalysts for the in situ production of hydrogen from methanol [122]. Correlative in situ X-Ray diffraction (XRD), High-Angle Annular Dark-Field Scanning Transmission Electron Microscopy (HAADF-STEM) 
and APT analysis reveals a bimodal distribution of large $\mathrm{Cu}$ particles $(4-8 \mathrm{~nm})$ together with very small copper clusters $(0.4-0.8 \mathrm{~nm})$ stabilized on a defective $\mathrm{ZnGa}_{2} \mathrm{O}_{4}$ spinel oxide surface. These small clusters are believed to be responsible for the high catalytic activity. Finally, Pt-Ru nanoparticles deposited on a Pt-Rh tip sample were successfully prepared with the electrophoresis method and show a partitioning between Pt-rich and Ru-rich regions [123]. Electrophoresis thus shows itself to be a straightforward route to APT analysis of nanoparticles; however, due to roughness of substrate needle's surface, aberrations can occur during the analysis and the data is not always of sufficient quality to get a detailed quantitative analysis in terms of 3D localization of the atoms on the atomic scale [124]: embedding methods can be used as an alternative.

\subsubsection{Imaging Core-Shell Au@Ag Nanoparticles-Embedding Method}

$\mathrm{Au} @ \mathrm{Ag}$ nanoparticles are used for preferential oxidation reactions (PROX) [125], for example the preferential oxidation of $\mathrm{CO}$ in presence of $\mathrm{H}_{2}$, important for fuel cell applications, and it is crucial to understand the structure/composition relationships to improve their synthesis and catalytic activity. Instead of using the electrophoresis method, an embedding method was used $[123,124]$. The first step consists of dispersing the nanoparticles on a substrate. Here, Au@Ag nanoparticles were dispersed in water, and subsequently deposited on a Si substrate (Figure 8a). The nature of the substrate and its structure are important parameters in the success of the sample preparation. The sample is then incorporated into a solid matrix, to obtain a continuous evaporation field during APT and to improve the data reconstruction. The solid matrix should be such that the field of evaporation is similar to that of the materials of interest. Different coatings were tested: $\mathrm{Pt}(\mathrm{C})$ from electron beam assisted deposition within the FIB instrument, and Cr by sputter coating (Figure $8 b, c$ ). The remaining of the sample preparation consists of the regular FIB lift-out method (Figure 8d). The authors claim that sandwiching the nanoparticles between two solid layers leads to the least artefacts during data reconstruction.
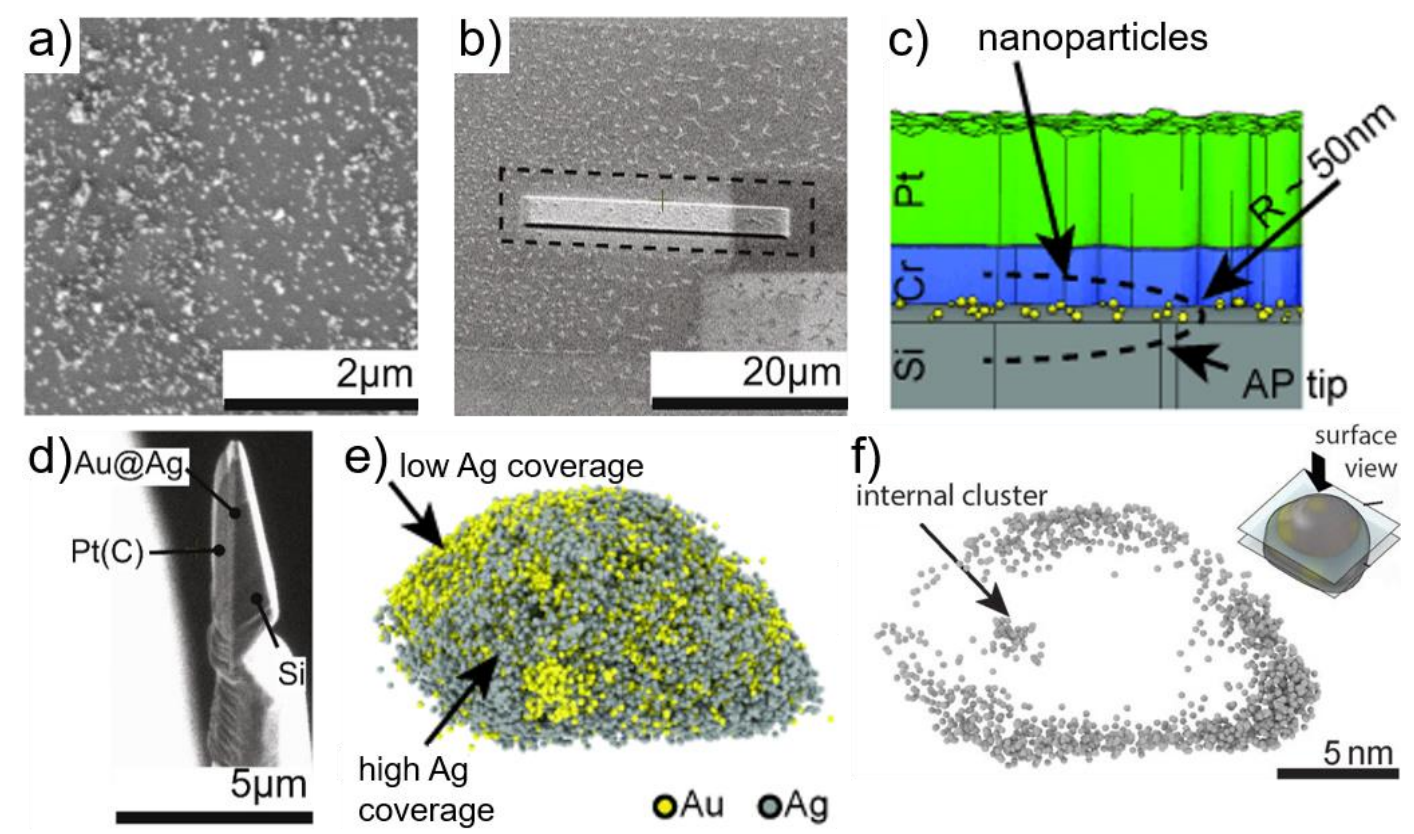

Figure 8. Investigation of Au@Ag nanoparticles prepared by the embedding method. (a) Dispersion of nanoparticles on Si substrate; (b) same sample after coating with $\mathrm{Cr}$ and $\mathrm{Pt}(\mathrm{C})$ strip; (c) schematic representation of the embedding method; (d) tip-sample after lift-out and before FIB milling: Au@Ag nanoparticles are sandwiched between the two solid layers; (e) atom map of a single nanoparticle highlighting the heterogeneous Ag surface coverage; and (f) $2 \mathrm{~nm}$ slice through the reconstruction showing the presence of an internal cluster. Panels $(\mathbf{a}, \mathbf{b}, \mathbf{d})$ : reprinted from [123], Copyright (2015), with permission from Elsevier. Panels (c,e-f): reproduced from [124]. Copyright (2014), John Wiley \& Sons, Ltd. 
The APT analysis reveals the presence of Au-Ag nanoparticles with a size of $\sim 15 \mathrm{~nm}$ made of $\mathrm{Au}$ core and Ag shell. However, the Ag surface coverage is not homogeneous, as depicted in Figure 8e, and the Ag surface concentration depends on the curvature of the specimen and on the size of the facets offering a way to fine-tune the synthesis of nanoparticles. More interestingly, $\mathrm{Na}$ and $\mathrm{N}$ species were detected in specific regions and are believed to originate from the nanoparticle synthesis [126]. Figure $8 \mathrm{f}$ represents a $2 \mathrm{~nm}$ cross-sectional slice where only $\mathrm{Ag}$ is depicted, highlighting the inhomogeneity of $\mathrm{Ag}$ at the surface, as well as the presence of Ag clusters within the nanoparticle. This study paves the way to better understand the residual concentration of spectator species and their influence on the synthesis and catalytic activity.

\subsubsection{Imaging Other Encapsulated Nanomaterials}

Several other nanomaterials were analyzed using different synthesis/encapsulation approaches. One example of analyzed unsupported catalysts by APT involves Ag nanoparticles produced by a gas condensation process [127], the terminated gas condensation method. A similar process was used in the past to deposit Au clusters on FIM tips [128-130]. This methodology allows the deposition of nanoparticles with a narrow size distribution without co-deposition of carbon-based support materials or surfactant that complicate the APT analysis. In addition, the preparation of specimens suitable for APT does not require a FIB lift-out step, reducing the preparation time. A uniform layer of Ag nanoparticles is deposited on a Si micro-post (Figure 9a). The nanoparticles are then encapsulated with a Pt layer with e-beam deposition (appearing as protrusions on Figure $9 b$ ), and subsequently milled by FIB to obtain a tip-sample suitable for APT experiments (Figure 9c). The 3D reconstruction of the specimen reveals the presence of isolated $\mathrm{Ag}$ nanoparticles (using the isosurface method) with a size matching the mass-selected clusters during the synthesis and the SEM analysis. Surprisingly, a significant amount of $\mathrm{Ag}$ is spread throughout in the analyzed volume rather than being confined in the nanoparticles. This could be due to trajectory aberrations during APT analysis, to surface mobility of Ag under electric field, or to the presence of individual Ag atoms at the surface of the Si micro-post. In addition, $\mathrm{Pt}, \mathrm{Ga}$ and $\mathrm{O}$ were detected, but the oxygen layer is relatively thin, indicating that the $\mathrm{Pt}$ capping layer successfully embedded and protected the nanoparticles from oxidation. Even though some improvements in the synthesis and analysis parameters are still needed, this approach allows for the analysis of narrowly distributed particles, without a time-consuming lift-out step, and with improved reconstruction as compared to electrophoresis-based depositions.
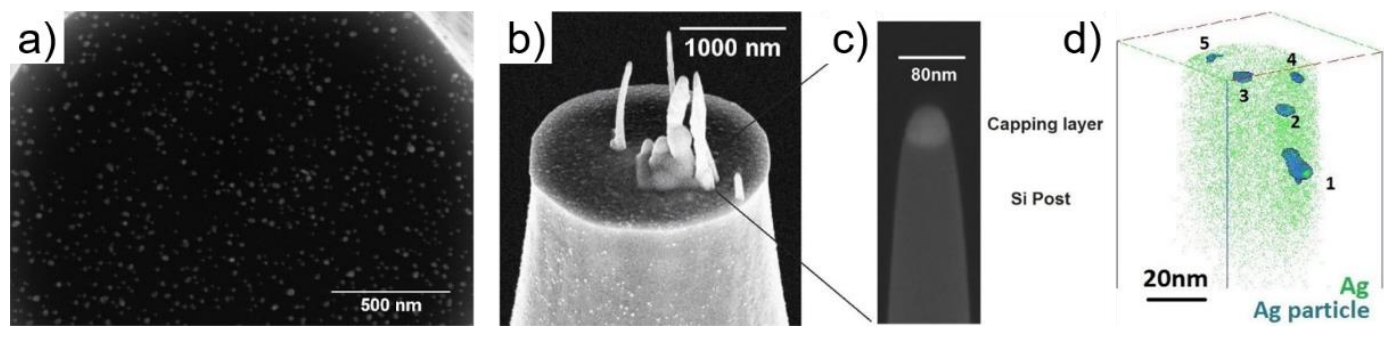

Figure 9. Study of Ag nanoparticles prepared by gas condensation process. (a) High density and clearly separated Ag nanoparticles on Si coupon; (b) e-beam deposition of Pt as embedding matrix; (c) final tip after FIB milling with nanoparticles embedded; and (d) 3D reconstruction showing the presence of isolated Ag nanoparticles and Ag atoms distributed throughout the tip-sample. Reprinted from [12777] under the terms of the Creative Commons Attribution License.

Alternative encapsulation methods have been used to analyze nanomaterials but could be extended to catalytic materials. The first one is the atomic layer deposition (ALD) method providing a high surface coverage, conformality and a void-free structure, which has been successfully applied to the investigation of Si nanowires embedded in $\mathrm{ZnO}$ [131], and Pt nanoparticles embedded in an $\mathrm{ZnO}: \mathrm{Al}$ matrix [132]. In another approach, a fusible bismuth-indium-tin alloy was used as embedding medium: Fe nanoparticles were dispersed on the fusible alloy and in situ melting was 
done in a FIB system [133]. This study revealed boron contamination from the synthesis. Finally, $\mathrm{Pd}$ and C-supported Pt nanoparticles were analyzed by APT using a methodology consisting of the electrophoretic deposition of nanoparticles on a flat $\mathrm{Cu}$ substrate followed by electrodeposition of a $\mathrm{Ni}$ film acting as an embedding matrix for the nanoparticles. Reliable APT data could be obtained for Pd nanoparticles, but the carbon-based support leads to artifacts [134]. All these alternate methods require a further FIB lift-out step to obtain a needle-shaped specimen. The next section aims at investigating supported catalysts, which is the next level of complexity.

\subsection{Catalysts as Supported Nanoparticles}

Many applications require the use of nanoparticles of catalysts dispersed on a support. The role of the support can be purely for the stabilization of the catalysts, i.e., to avoid the coalescence of nanoparticles and ensure a high specific surface area [135,136], but can also enhance the reactivity by charge transfer [137] or participate in the catalytic process [138-142]. This section focuses on the study of metallic particles embedded in a metal-oxide matrix, and on the study of C-supported catalysts.

\subsubsection{Oxide-Supported Nanoparticles}

Metallic nanoparticles dispersed on oxides are widely used for catalytic applications, and their characterization remains challenging. Due to a heterogeneous field of evaporation, the analysis of interfacial regions leads to trajectory aberrations, local magnifications and reconstruction artifacts [143]. Furthermore, it is quite common to observe a thin layer of oxide at the metal/metal-oxide interface due to field-induced oxygen migration: oxygen reacts with the metal and forms an additional interfacial oxide layer [144]. Correlative approaches are thus required to improve the compositional and spatial resolution of such samples [145].

Model metallic nanoparticles dispersed in a metal oxide were studied, consisting of $\mathrm{Au} / \mathrm{MgO}$ and $\mathrm{Ag} / \mathrm{MgO}[146,147]$. The samples were synthesized by ion implantation and annealing [148], and APT specimens were prepared by the conventional lift-out method [149]. As expected, the analysis reveals the presence of Au nanoclusters, but diluted, i.e., with a maximum of $\sim 20 \%$ of $\mathrm{Au}$ within the cluster. Correlative approaches were thus needed to improve the compositional and spatial resolution. APT, STEM and finite element field evaporation modeling were used to analyze the $\mathrm{Au} / \mathrm{MgO}$ system in detail [150]. APT-STEM reveals that the number of nanoparticles within the $\mathrm{MgO}$ matrix is similar between the two methods, but their shape appears distorted in the APT reconstruction (Figure 10a-c). 

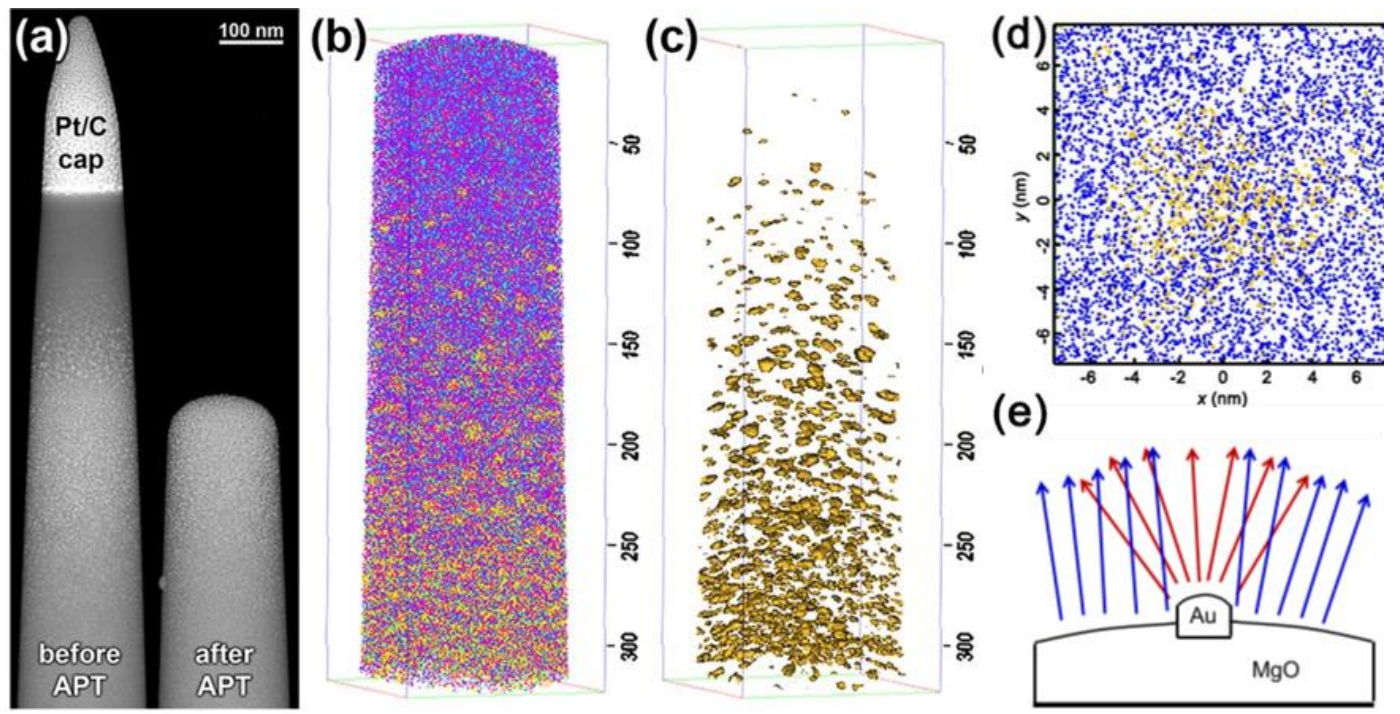

Figure 10. Correlative APT-STEM study of $\mathrm{Au} / \mathrm{MgO}$ system as supported catalyst. (a) HAADF-STEM image of the specimen before and after APT experiments to correlate the morphology of Au nanoparticles; (b) 3D atom map of the specimen analyzed by APT (O is represented as cyan, $\mathrm{Mg}$ as magenta and $\mathrm{Au}$ as yellow); (c) 3D maps representing only Au-rich regions (by applying the isosurface method); (d) individual cluster highlighting the presence of a diffuse $\mathrm{Au} / \mathrm{MgO}$ interface and the presence of $\mathrm{MgO}$ within the Au nanoparticle; and (e) schematic representation of the Au protrusion leading to trajectory overlaps and local magnification. Panels (a-d): reprinted with permission from [150]. Copyright (2014) American Chemical Society. Panel (e): reprinted with permission from [149150]. Copyright (2012) Cambridge University Press.

Moreover, APT analysis yielded 1D concentration profiles in the vicinity of the nanoparticles in which the apparent extent of $\mathrm{Au} / \mathrm{MgO}$ interdiffusion scaled with the size of the Au-rich regions, even though STEM results exhibit an abrupt $\mathrm{Au} / \mathrm{MgO}$ interface (Figure 10d). The difference in fields of evaporation of $\mathrm{Au}$ and $\mathrm{MgO}$ leads to a preferential evaporation of $\mathrm{MgO}$, which results in $\mathrm{Au}$ nanoparticles protruding from the hemispherical surface of the evaporating specimen. The local magnification (Figure 10e) due to the protruding Au generates trajectory overlaps and results in inaccurate composition and incorrect interface width measurements. Experimental parameters, such as the laser pulse energy, have to be optimized to obtain reliable data, for example detecting stoichiometric $\mathrm{MgO}$ ions rather than complex $\mathrm{Mg}_{\mathrm{x}} \mathrm{O}_{\mathrm{y}}$, as well as to decrease background noise and to improve the sensitivity [146,151].

\subsubsection{Carbon-Supported Nanoparticles}

Another type of support commonly used for catalytic and electrocatalytic applications is based on high surface area porous carbon, and different $C$-supported commercial catalysts were analyzed by APT [121]: C-supported Pt, Pt/Co, and Ir@Pt nanoparticles. The samples were first dissolved in a methanol/water solution prior to sample preparation by electrophoresis. Several difficulties may arise in the analysis of such materials: the presence of a porous support; the number and location of particles influencing the evaporation rate across the specimen; and the evolution of the model geometrical shape during the experiment; three factors strongly influencing the accuracy of the 3D reconstructions. Optimized reconstructions were obtained by correlating the particles shape and size with TEM imaging.

As a first set of experiments, $\mathrm{Pt}$ nanoparticles deposited on a porous $\mathrm{C}$ substrate were investigated and reveal a relatively complex morphology (Figure 11a) with $\mathrm{Pt}, \mathrm{C}, \mathrm{C}_{\mathrm{x}} \mathrm{H}_{\mathrm{y}}$ and Na species detected (as well as traces of $\mathrm{Cl}$ ). The nanoparticles appear to be enveloped in a layer of carbon-based materials, and thin slices of the 3D reconstruction not only show the position of $\mathrm{Pt}$ and C-based species in the 
specimen (Figure 11b,c), but also reveal the presence of low-density regions, due to the porous nature of the support. A variation of the particle size as a function of the depth of analysis is observed and is in agreement with TEM experiments. An important observation is the presence of $\mathrm{Na}^{+}$ions in the 3D reconstruction, and control experiments were performed by probing (1) the Pt- $\mathrm{Rh}$ tip prior to any deposition (Figure 11d), (2) the tip after unsuccessful deposition of materials, in absence of $\mathrm{Pt}$ nanoparticles (Figure 11e); and (3) the tip after deposition of C-supported Pt (Figure 11f). In the first case, only Pt and Rh ionic species are detected, as expected. In the second case, water and C-based species are detected which originate from the carbon support, surfactant from the synthesis or fragment of methanol. In the last case, $\mathrm{Na}^{+}$ions are present in the mass spectra and the reconstruction reveals that they appear in association with $\mathrm{C}_{\mathrm{x}} \mathrm{H}_{\mathrm{y}}$ species, not with $\mathrm{Pt}$. The hypothesis is that these impurities were introduced during the original synthesis. Since such impurities may affect the catalytic activity and increase the nanoparticle's sintering [152], their presence should be avoided, and the washing steps should be improved.
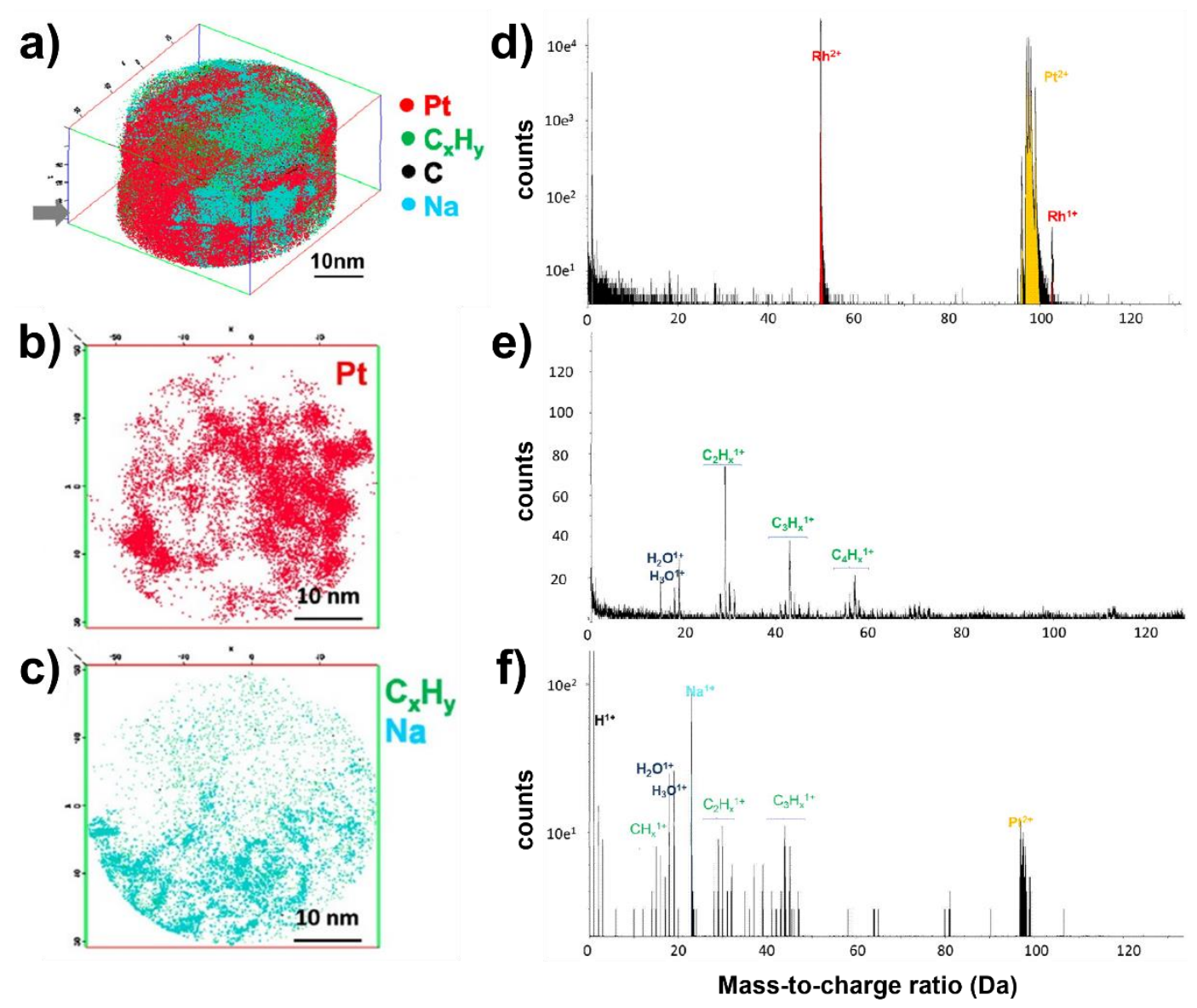

Figure 11. Investigation of C-supported Pt nanoparticles. (a) 3D reconstruction of the specimen presenting a complex morphology; $5 \mathrm{~nm}$ slice of the 3D map (from the grey arrow) representing the distribution of (b) Pt; and (c) C-based species and Na; mass spectra of a Pt-Rh tip sample (d) before any deposition where only $\mathrm{Pt}$ and $\mathrm{Rh}$ species are detected; (e) after deposition of $\mathrm{C}$-support in methanol/water solution (in absence of $\mathrm{Pt}$ nanoparticles): only fragments of methanol $\left(\mathrm{C}_{2} \mathrm{H}_{\mathrm{x}}{ }^{1+}, \mathrm{C}_{3} \mathrm{H}_{\mathrm{x}}{ }^{1+}, \mathrm{C}_{4} \mathrm{H}_{\mathrm{x}}{ }^{1+}\right)$ and water $\left(\mathrm{H}_{2} \mathrm{O}^{1+}, \mathrm{H}_{3} \mathrm{O}^{1+}\right)$ are detected; $(\mathbf{f})$ after deposition of $\mathrm{C}$-supported Pt nanoparticles showing the presence of methanol and water fragment, as well as the expected $\mathrm{Pt}^{1+}$ species and the non-expected $\mathrm{Na}^{1+}$ from the synthesis. Reprinted with permission from [121]. Copyright (2014) American Chemical Society.

$\mathrm{Pt} /$ Co supported nanoparticles were analyzed with a similar methodology. With high loading of $\mathrm{Pt} / \mathrm{Co}$ nanoparticles and possible agglomeration, the boundary between two distinct particles is not well-defined, which highlights the importance of good dispersion for such studies. For this analysis, 
only well-defined and isolated particles were taken into account, and the analysis reveals individual composition ranging from 0.7 to 23.2 at.\% of Co (as compared to the nominal composition of 25.3 at.\%), which composition distribution will undoubtedly affect the catalytic activity. The authors also emphasize that the magnetism of $\mathrm{Pt} / \mathrm{Co}$ depends on the Co content, and that electrophoresis might selectively deposit certain compositions (although electrophoresis is not an inherently magnetic phenomenon). Additionally, supported core-shell Ir@Pt nanoparticles were probed revealing the presence of core-shell structure with significant intermixing of $\mathrm{Pt}$ and Ir within the layers, but also duplex structures, suggesting a relatively low control during the synthesis. Since detailed atomic-scale chemical information is vital to understanding the structure-activity relationship, the three examples presented prove that APT can be used for the quality control of synthesized nanoparticles, giving better insights into the presence of impurities, the size and concentration distribution, as well as the structure of the particles. However, the presence of porous carbon support, and more generally of porous materials, remains an issue for APT experiments.

One more example is the study of graphite-supported Cu-based catalysts [153], graphite being used to minimize the presence of a porous support such as $C$ black. After hydrogenation of the sample, the catalyst is present as isolated and dispersed nanoparticles $(12-15 \mathrm{~nm})$ and agglomerates $(1-3 \mu \mathrm{m})$. The dispersion being too low to ensure a statistical representation of nanoparticles within the APT specimen, an agglomerate was selected, transferred to a micro-post and then FIB milled into a sharp tip. Between every steps of the milling, e-beam assisted deposition of $\mathrm{Pt}$ was performed to ensure structural stability of the sample and fill the pores. The presence of nanoparticles within the agglomerate can be observed in the 3D reconstruction, proving that APT can be used for materials of increasing complexity. Powders of catalysts and the development of innovative sample preparation to analyze them by APT will be discussed in the next section.

\subsection{Catalysts as Powder}

The preparation of samples as powders has attracted attention since the early years of atom probe, and one of the important points is to prepare APT specimens without altering the microstructure of the materials. If the sample is large enough, i.e., micrometer-sized powder particles, and if pores are absent from the powder, a conventional lift-out procedure can be used without the use of embedding matrix [154-156]. Alternatively, a single powder particle can be mounted on a micro-post and then FIB milled [157]. If the size and porosity of the sample does not allow for conventional sample preparation, encapsulation within a tube can be used. The first attempt at this technique consisted of compacting the powder of interest in a $\mathrm{Cu}$ tube, cold-swaged down to a diameter of 200-300 nm; electrochemical etching was then used to sharpen the sample and analyze $\mathrm{Cu}-\mathrm{Ag}$ particles by APFIM [158-160]. More recently, a glass-fiber micro capillary was filled with powder of steel/ $\mathrm{Ni} / \mathrm{Cr}$, heated and extended with constant force fiber extractor to produce APT specimen suitable for analysis [161].

In addition to the lift-out and tube encapsulation methods, a powder solidification procedure has been developed for the analysis of CoCuMn powder catalysts [123,162]. Co-based materials are used for the Fischer-Tropsch reaction, i.e., the CO hydrogenation to produce long-chain hydrocarbons or alcohols $[163,164]$. CoCuMn catalysts, prepared by co-precipitation of metal salts into oxalate precursors, allow for the production of long-chain 1-alcohols with high selectivity (up to 95\%) while maximizing the yield of $\mathrm{C}_{8}-\mathrm{C}_{14}$ terminal alcohols. Such catalysts are produced in the form of powders (Figure 12a), without the presence of a classical support. However, the voids within the powder needs to be replaced by an APT-compatible material to maintain structural integrity and avoid trajectory aberrations [79]. After dispersion of the catalyst on a substrate, an in situ micro-gripping system is used to pick up and manipulate an agglomerate of appropriate size $(\sim 2-3 \mu \mathrm{m})$ [123]. The specimen is then forced onto a sharp micro-post (Figure 12b) and fixed with a layer of e-beam assisted deposition of Pt (Figure 12c-left). FIB pyramid milling (Figure 12c) and annular milling are applied to obtain the APT tip sample. 

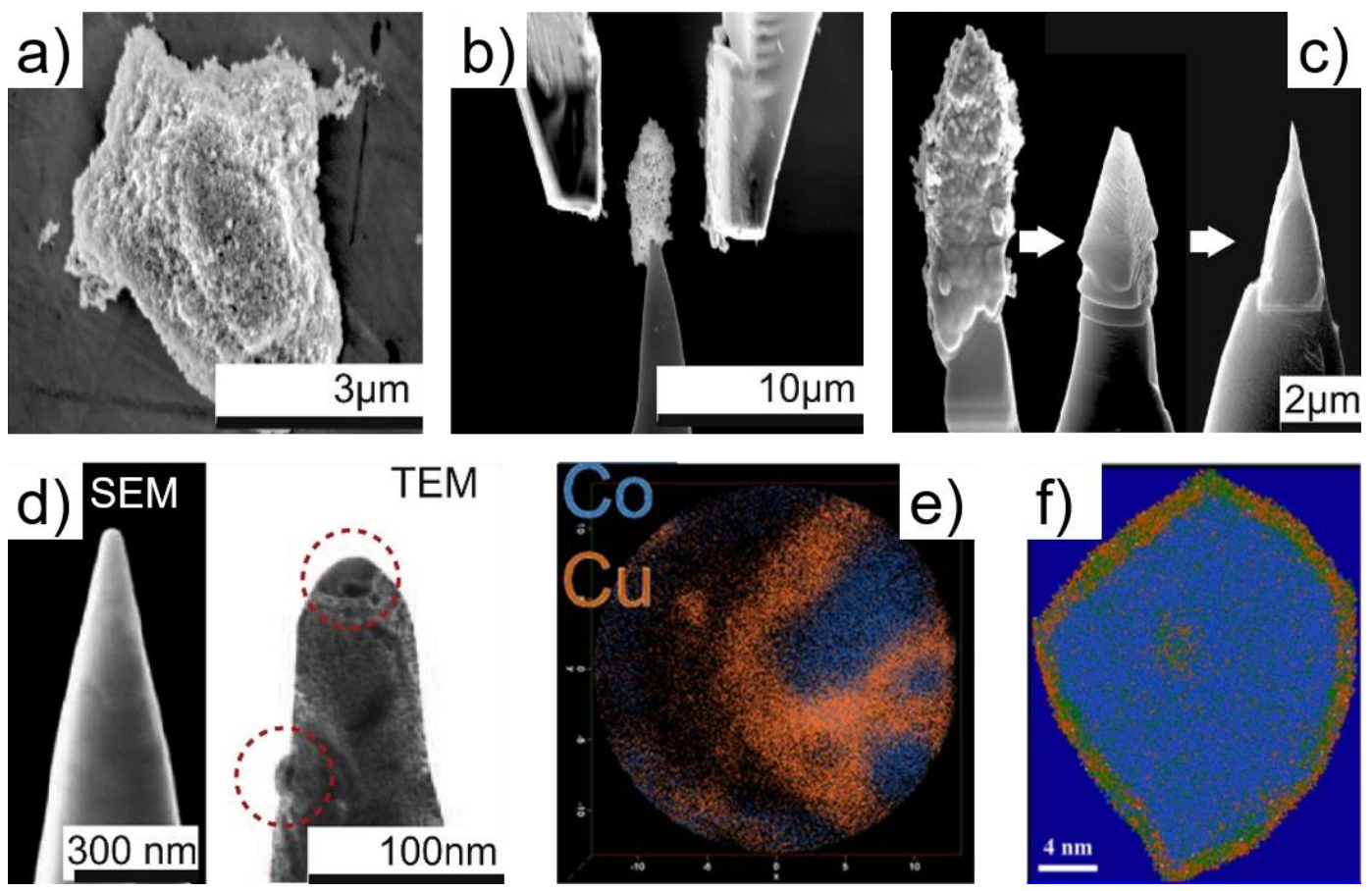

Figure 12. Sample preparation and resulting APT experiment of CoCuMn catalyst as powder. (a) particle agglomerate; (b) in situ micro-gripper used to force the catalyst on a sharp micro-post; (c) e-beam assisted Pt deposition and pyramid milling; (d) final smooth and void-free tip morphology imaged by SEM and TEM (two particles of 20-30 nm are highlighted); (e) top view of the APT detector during APT experiment; and (f) 3D reconstruction of a particle with core-shell structure ( $\mathrm{Cu}$ is depicted as orange, Co as blue, $\mathrm{Mn}$ as green and $\mathrm{O}$ as white). Panels (a-d): reprinted from [123], Copyright (2015), with permission from Elsevier. Panel (e): reprinted with permission from [79]. Copyright (2017) Cambridge University Press. Panel (f): reprinted with permission from [162]. Copyright (2013) American Chemical Society.

The originality of the procedure is that the annular milling is performed under a constant flow of gaseous precursor while imaging the tip with the electron beam at high current and energy, inducing deposition of $\mathrm{Pt}$ within the voids between the particles. This produces a nearly void-free solid matrix for the specimen of interest, as can be seen on the final tip by SEM and TEM (Figure 12d) where two large particles are highlighted. For the powder lift-out, or powder solidification, procedure to be successful, a good adherence between the matrix and the particles is required, and a high purity matrix allows for improved quality data with fewer decomposition products in the mass spectra. The analysis of the specimen (Figure 12e) reveals its atomic structure with a Co-rich core and a Cu-dominated CoCuMn mixed shell (Figure 12f) responsible for the catalytic activity. This shell is $\sim 2 \mathrm{~nm}$ thick, and oxygen atoms are distributed at the core/shell interface.

A similar catalyst, $\mathrm{Co}_{4} \mathrm{Mn}_{1} \mathrm{~K}_{0.1}$, also produced by co-precipitation, favors selectivity towards the formation of aldehydes [165]. The APT analysis of CoMnK post-reaction reveals the formation of a cobalt carbide phase $\left(\mathrm{Co}_{2} \mathrm{C}\right)$ and low concentration of $\mathrm{Mn}$ and $\mathrm{K}$ in the outer layers only [166]. These studies show that "CoCuMn" core-shell particles with tailored shell composition and "CoMnK" particles are highly efficient catalysts for the Fischer-Tropsch reaction, and only high-resolution techniques such as APT can accurately reveal the 3D structure and composition of the core-shell structures.

\subsection{Catalysts as Porous Materials—Nanoporous Au}

As previously mentioned, voids or deprocessed materials needs to be filled with APT-compatible materials for a better accuracy of the APT data [164]. This becomes extremely important for self-supported nanoporous catalysts where the porosity can be as high as 70\%. Catalysts in the form of nanoporous bulk materials have recently attracted much attention due to their high surface-to-volume 
ratio, their mechanical stability, their porosity allowing for mass transport of reactants and products, their absence of support, and most of all, due to their activity towards oxidation reactions [104-107,167-169]. These structures are produced by dealloying methods, i.e., the selective etching of the least noble metals from an initial alloy $[170,171]$, and the chemical nature, concentration and nanoscale spatial distribution of the residual elements greatly influences the dealloying kinetics, the morphology and the catalytic activity; nanoscale characterization is thus required. To investigate such open-cell structures and avoid overlapping ion trajectories and distorted reconstructions, specific sample preparation methods have been developed using electron-beam assisted deposition within the FIB system and using electrodeposition.

The first example consists of the analysis of $\mathrm{Au}_{30}-\mathrm{Ag}_{70}$ materials dealloyed in $\mathrm{HNO}_{3}$ by free corrosion [172], generating a nanoporous gold sample-npAu—with pores of $\sim 50 \mathrm{~nm}$ in diameter (Figure 13a-inset). Two precursors were used to fill the pores and get a compact material: $\mathrm{Co}_{2}(\mathrm{CO})_{8}$ and $\mathrm{Fe}_{2}(\mathrm{CO})_{9}$, both precursors yielding relatively high purity metals as compared to more classical precursors (Pt- and W-based). Several parameters are used to optimize the penetration and filling depth of the metals into the high-aspect ratio npAu: beam acceleration voltage, beam current, dwell time, pattern type and deposition time. Further FIB-milling produces suitable specimens for APT analysis (Figure 13a). The analysis shows that both Co- and Fe-based fill yields reliable APT data when acquired using voltage-pulse mode, with Fe-based precursor yielding more stable specimens. In Figure 13b, the mass spectra resulting from Fe-filled npAu shows the presence of the expected $\mathrm{Au}$, Fe-based species, but also the incorporation of $\mathrm{H}_{2} \mathrm{O}$ into the deposit, probably due to contamination during transfer. Interestingly, Ag is absent from the mass spectra. A 3D reconstruction (Figure 13c) reveals that atomic planes, separated by a distance of $0.23 \mathrm{~nm}$ corresponding to $\mathrm{Au}\{111\}$ planes, can be observed, highlighting the high resolution of the technique. The analysis of the interface proves that there is no significant local variation in composition. The authors also mentioned that $\mathrm{Pt}$ deposition precursors do not allow for stable APT experiments under voltage-pulse mode. Further work proved that Pt-based precursor as a filling material allows for npAu analysis by APT in laser pulse mode $[173,174]$, emphasizing the importance of acquisition parameters.

The second set of experiments uses an alternative procedure to fill the pores by electrodeposition $[175,176]$. Electrodeposition of metals on a porous structure can lead to incomplete filling, clustered deposition and inhomogeneous filling [177-179]. $\mathrm{Au}_{23}-\mathrm{Ag}_{77}$ materials were electrochemically etched in $\mathrm{HClO}_{4}$ aqueous solution, and electrodeposition of $\mathrm{Cu}$ was performed from a $\mathrm{CuSO}_{4}+\mathrm{H}_{2} \mathrm{SO}_{4}$ solution. Some regions of the specimen were not $\mathrm{Cu}$-filled, due to deficient $\mathrm{Cu}$ concentration in the solution, but these regions were removed during FIB-milling (Figure 14a). The partial dealloying leads to the formation of a porous structure with $\sim 10 \mathrm{~nm}$ large ligaments and pores. Due to the differences in evaporation fields between $\mathrm{Au}$ and $\mathrm{Cu}$, the field evaporation behavior is complex and leads to trajectory aberrations, and subsequently, to an overlap of $\mathrm{Cu}$ and $\mathrm{Au}+\mathrm{Ag}$ phases at the interfacial regions. Despite this, a qualitative analysis (Figure 14b,c) shows compositional variation within the structures of one single ligament (black arrow in Figure 14b): the outermost part of the ligament is Au-enriched, whereas the core is Ag-rich with a composition at the center part close to the initial alloy composition. At the surface of the ligaments, some Ag-rich areas are also present, signs of a heterogeneous surface composition, which is an important finding since the functionality of nanoporous materials is affected by the ligament size, the local and the global chemical composition. It can also be concluded that electrodeposition is an efficient procedure to fill pores with diameters of $\sim 10 \mathrm{~nm}$. We also note that further work used $\mathrm{Ni}$ to successfully fill the pores in npSi and that the correlation between electron tomography and atom probe tomography experiments in these systems allows for more accurate 3 D reconstructions [180]. 

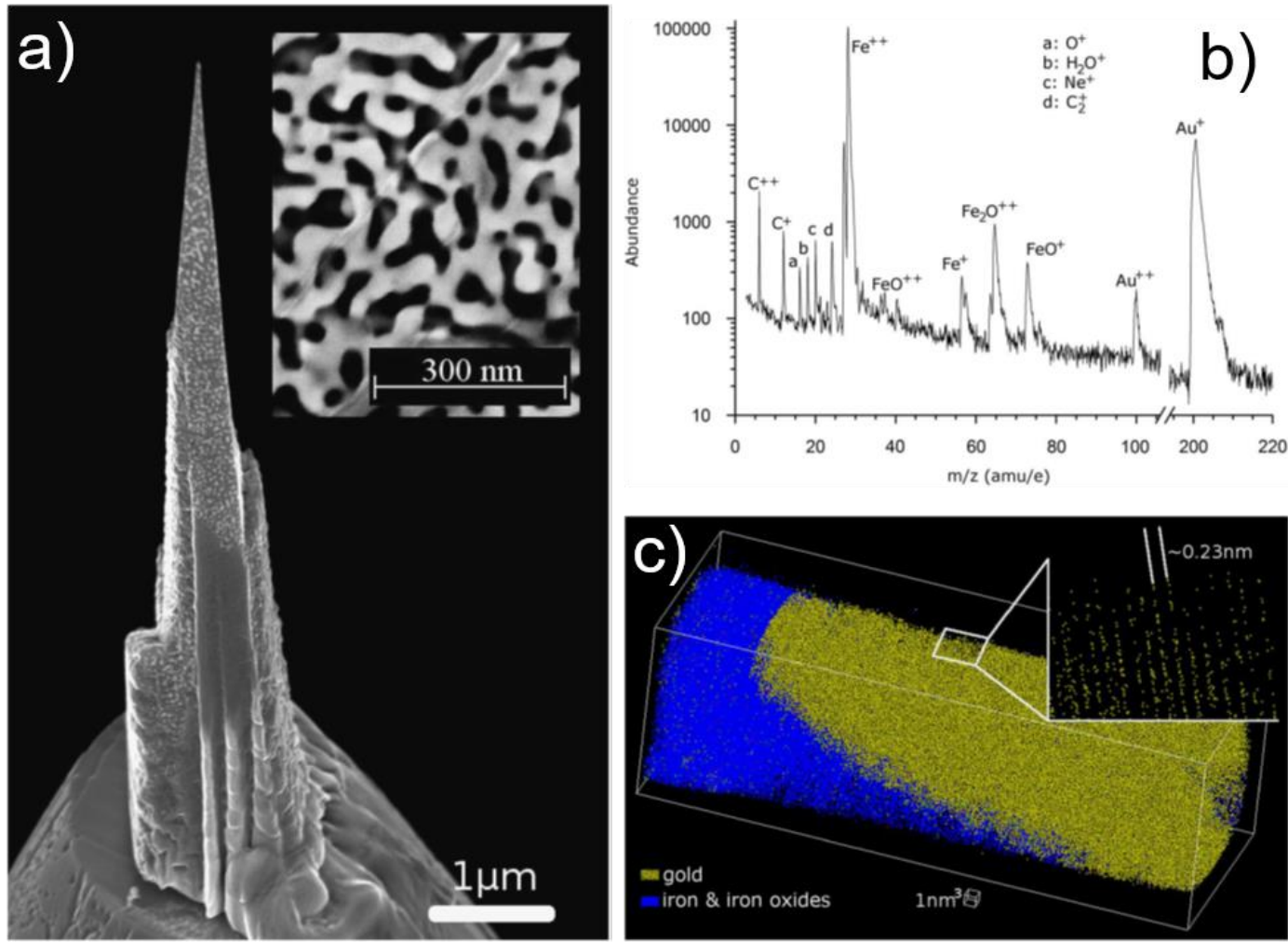

Figure 13. Self-supported nanoporous Au. (a) SEM image of the npAu structure (inset) and of a tip-sample after filling the voids by e-beam assisted deposition; (b) mass spectra from Fe-filled npAu revealing the presence of traces of contaminations and the absence of Ag; and (c) 3D reconstruction of a partial ligament and its interface with Fe-filling materials. Atomic depth resolution is obtained on Au. Reprinted with permission from [172]. Copyright (2015) Cambridge University Press.
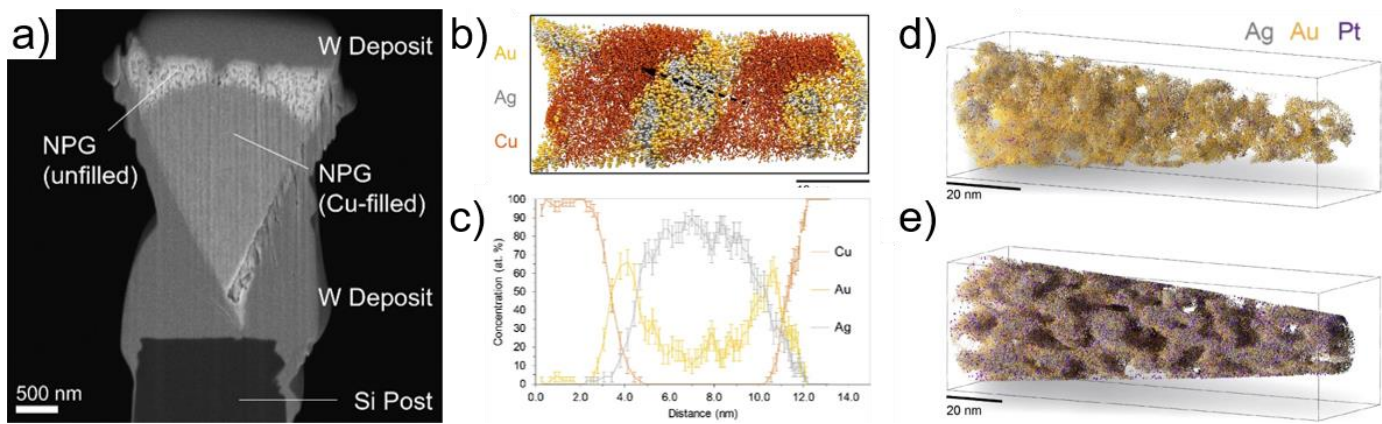

Figure 14. Exploring the effect of Pt on the structure of npAu. (a) SEM image after lift-out (and before FIB milling) of a partially filled npAu sample by Cu electrodeposition; (b) 3D atom map of a npAu specimen filled with $\mathrm{Cu}$; and (c) 1D concentration profile along the black arrow in (b) highlighting the core-shell ligament structure with Au-rich shell and Ag-rich core. Trajectory overlaps between the $\mathrm{Cu}$ and the $\mathrm{Au}+\mathrm{Ag}$ phases leads to a rather wide interface; 3D reconstruction of (d) dealloyed $\mathrm{Ag}_{77} \mathrm{Au}_{22} \mathrm{Pt}_{1}$ and (e) dealloyed $\mathrm{Ag}_{77} \mathrm{Au}_{20} \mathrm{Pt}_{3}$ specimen showing different ligament and pore size due to the different Pt content. Panel (a): reprinted from [175], Copyright (2017), with permission from Elsevier. Panels (b-e): reprinted from [176], Copyright (2018), with permission from Elsevier.

Further experiments were performed on npAu with small amounts of $\mathrm{Pt}$, which is known to stabilize the nanoporous structure, to avoid coarsening in oxidizing environments, and to enhance the (electro)catalytic activity [181,182]. These effects are supposed to be due to Pt segregation at step and kink sites where they can inhibit the mobility of step edges. Two alloys were studied using the same electrochemical etching and $\mathrm{Cu}$ electrodeposition procedure: $\mathrm{Ag}_{77} \mathrm{Au}_{22} \mathrm{Pt}_{1}$ and $\mathrm{Ag}_{77} \mathrm{Au}_{20} \mathrm{Pt}_{3}$, resulting 
in $n p A u(P t 1)$ and $n p A u(P t 3)$. APT was used to explore the effect of Pt on the dealloying behavior and how the Pt concentration affects the morphology of the final structure $[176,183]$. A detailed analysis shows that, associated with the higher $\mathrm{Pt}$ content in $\mathrm{npAu}(\mathrm{Pt} 3)$, strong $\mathrm{Pt}$ segregation occurs, leading to an increased retention of Ag during dealloying as compared to $\mathrm{npAu}(\mathrm{Pt} 1)$. This translates into finer ligament sizes in $n p A u(P t 1)$, and finer pores in $n p A u(P t 3)$. Therefore, it is possible to improve the stability of a npAu structure, and to generate various ligament/pore sizes, by tuning the composition of a third element in the initial alloy, an effect that is revealed with unprecedented resolution by APT.

\subsection{Catalysts as Porous Materials-Zeolites}

Zeolites are a class of microporous crystalline materials made from aluminosilicates. With their high surface area, tunable pore and channel sizes, adjustable acidity/basicity and ion exchange properties, zeolites are widely used as catalysts [184-187]. Due to the different charge of Si and Al units, the $\mathrm{Si} / \mathrm{Al}$ ratio within the zeolite guides the acidity of the zeolite, and subsequently, its activity and selectivity. Determining the quantitative spatial distribution of active sites is therefore of utmost importance to better understand the reactivity of this class of catalysts, and APT is able to provide such information. As described in [188], the critical aspects of zeolite material analysis by atom probe are, among others:

- $\quad$ the sample preparation, due to heterogeneous distribution of elements at the microscale;

- $\quad$ the proper assignment of mass spectra peaks, due to the complex fragmentation patterns of carbon-based materials and the lack of fingerprint fragmentation patterns in APT;

- $\quad$ the limitation of spatial resolution, blurring the atomic positions;

- $\quad$ the proper statistical data analysis.

In searching for chemical heterogeneities to assess the structure-composition-reactivity relationships, different data treatments can be used: iso-concentration surfaces and 1D-concentration profiles to visualize phase separation; nearest neighbor distributions to discover the presence of precipitates and their short-range distributions; radial distribution functions to examine affinity between species, especially at short distances; and cluster analysis to isolate clusters (down to 10 atoms) within a matrix [188].

The first APT analysis of zeolites consisted of the ZSM- 5 crystal (Figure 15a) before and after steam treatment [189], which is a common post-synthesis process to either stabilize or deactivate the ZSM-5 zeolite [190]. The specimen was prepared by conventional lift-out method (Figure 15b). However, Ga-ion beam damage leads to the formation of an amorphous phase, and thus low ion beam current is necessary, even though the outermost part of the tip sample remains amorphous (Figure 15c,d). Before any treatment, the distributions of $\mathrm{Si}, \mathrm{O}$ and $\mathrm{Al}$ within the zeolite are rather homogeneous (Figure 15e). After steam-treatment of the specimen, the $\mathrm{Al}$ distribution becomes heterogeneous, with formation of Al-rich clusters within the bulk, and segregation at a grain boundary (Figure $15 \mathrm{f}$ - the blue and yellow dots on this figure represent the protective layer deposited for FIB sample preparation). Further distribution analysis reveals a shorter most probable distance and higher $\mathrm{Al}$ density in the steam treated sample (18 $\pm 6 \AA$ and 0.025 atoms.nm ${ }^{-3}$ in the untreated sample vs. 0.5 atoms.nm ${ }^{-3}$ and $9 \pm 3 \AA$ in the treated sample). 

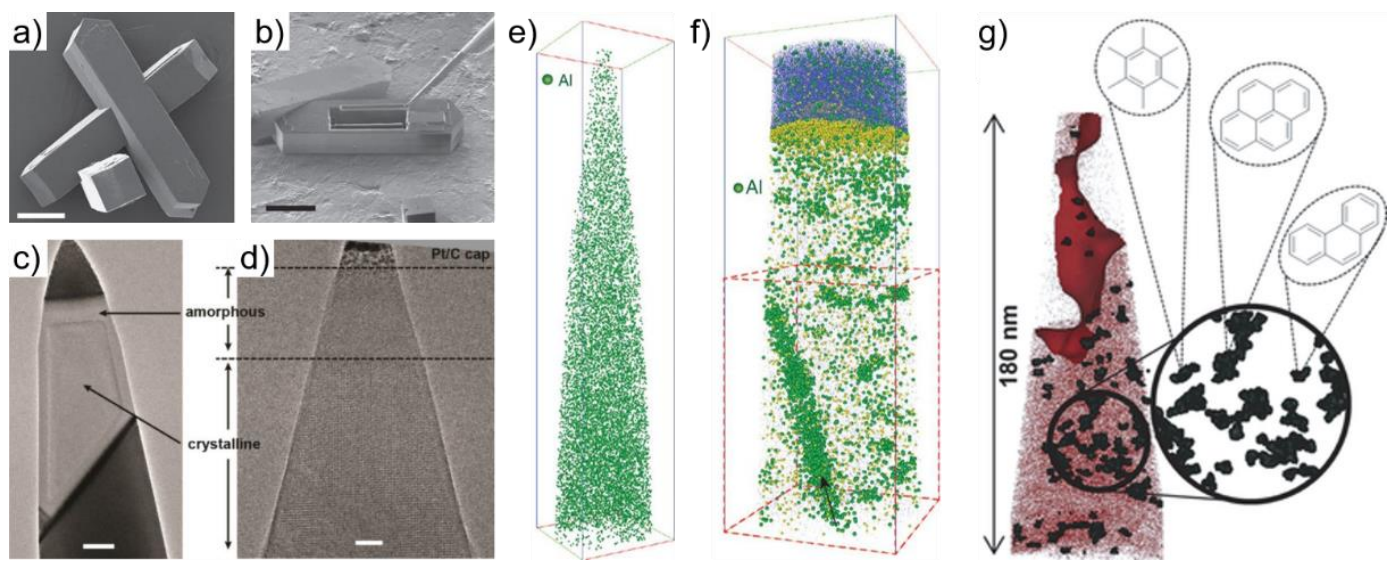

Figure 15. Towards the analysis of zeolites by APT. (a) Helium Ion Microscope image of a ZSM-5 sample (scale bar: $20 \mu \mathrm{m}$ ); (b) sample preparation by FIB lift-out (scale bar: $25 \mu \mathrm{m}$ ); (c) and (d) TEM of the APT specimen highlighting the damage suffered during sample preparation: the crystalline structure is embedded in an amorphous shell due to Ga implantation (scale bars: (c) $100 \mathrm{~nm}$ and (e) $20 \mathrm{~nm}$ ); 3D atom map of the Al distribution within a ZSM-5 specimen (e) before any treatment, representing a homogeneous distribution and (f) after steam treatment, where the formation of $\mathrm{Al}$ clusters is apparent, as well as segregation to a grain boundary; (g) coke formation on a ZSM-5 zeolite after methanol-to-hydrocarbon reaction using ${ }^{13} \mathrm{C}$ label. The red dots correspond to ${ }^{13} \mathrm{C}$ atoms, and the black regions correspond to ${ }^{13} \mathrm{C}$-clusters, with possible coke species produced (consistent with the cluster size, even though APT do not provide such detailed molecular fingerprints). Panels (a-f): reprinted from [18977] under the terms of the Creative Commons Attribution License. Panel (g): reprinted from [191] under the terms of the Creative Commons Attribution License.

ZSM-5 crystals were also studied after partial deactivation due to methanol-to-hydrocarbons reaction (after $90 \mathrm{~min}$ of reaction at $623 \mathrm{~K}$ ) using ${ }^{13} \mathrm{C}$-labeled methanol to assign the presence of ${ }^{13} \mathrm{C}$ to the reaction rather than any other sources [191]. The coke formation resulting from this reaction is known to emerge from the formation of polycyclic aromatics near channel intersections and pore openings, leading to a blockage of the pores and deactivation of the zeolite [192,193]. Using cluster analysis and iso-concentration surfaces, the presence of ${ }^{13} \mathrm{C}$ agglomerates, with a median size of 30-60 ${ }^{13} \mathrm{C}$ atoms, was revealed (Figure $15 \mathrm{~g}$ ), indicating the presence of several aromatic cycles, even though the APT technique is unable to provide molecular fingerprinting information of the ${ }^{13} \mathrm{C}$ clusters detected. It was also discovered that, within the ${ }^{13} \mathrm{C}$ clusters, the $\mathrm{Al}$ concentration was significantly higher than in the bulk, leading to an increased Brønsted acid site density. The coke formation can therefore be linked to the $\mathrm{Al}$ concentration, which reflects the acidity, down to the nanoscale. Such a study provides important insights into the coke formation mechanism. Using SAPO-34 instead of H-ZSM- 5 catalysts also showed that coke formation during the methanol-to-hydrocarbons reaction correlates with the presence of acid sites, with differences in the cluster number, cluster size, and number of coke-depleted regions between the two catalysts [194]. Similar experiments were performed regarding the ethanol-to-hydrocarbon reaction [195] run for a longer time (72 h) to assess the industrial relevance of the analysis. Similarly to [191], a non-uniform distribution of Al and the formation of C-rich region can be observed after reaction, showing the usefulness of the APT methodology to study the coke formation in zeolites. With its unique spatial resolution, a homogeneous distribution of $\mathrm{P}$ after impregnation of a HZSM- 5 zeolite, without significant removal of Al, can also be probed by APT [196].

Another type of zeolite studied by APT is the SSZ-13 for selective catalytic reduction [187]. The analysis of Fe-SSZ-13 after hydrothermal aging demonstrates that the Fe distribution remains homogeneous, but the authors mentioned that the results should be treated with caution since the size of the APT specimen is smaller than an individual SSZ-13 zeolite particle [197]. Cu-exchanged zeolite catalysts are also used for selective catalytic reduction systems due to their high activity and stability [198-200]. Cu-ZSM-5 and Cu-SSZ-13 zeolites were aged using industry standard protocol to 
simulate 135,000 miles of vehicle use and then analyzed by APT [201,202]. In both cases, some material destruction occurred after aging due to $\mathrm{Al}$ removal from the framework. The difference in deNOx reactivity between $\mathrm{Cu}-\mathrm{SSZ}-13$ and $\mathrm{Cu}-\mathrm{ZSM}-5$ can be assigned to the changes in both $\mathrm{Cu}$ and $\mathrm{Al}$ spatial distribution between fresh and aged catalysts. Some $\mathrm{Cu}$ and $\mathrm{Al}$ clustering occurs in the Cu-SSZ-13 catalyst, whereas a strong segregation of $\mathrm{Cu}$ and $\mathrm{Al}$ in the form of $\mathrm{CuAl}_{2} \mathrm{O}_{4}$ spinel phase takes place in the $\mathrm{Cu}-\mathrm{ZSM}-5$ catalysts. It is thus possible to correlate the activity and stability of zeolites with the formation of heterogeneities and/or the formation of inactive phases at the nanoscale level by APT.

\section{Conclusions and Perspectives}

It is important for the interested researcher to note that the analysis of catalytic and electrocatalytic materials by APT is still an emerging field. The examples presented in this review highlight the current and future importance of atom probe tomography for catalysis applications. First, the analysis of model tip-samples allowed visualization of diffusion and segregation processes, as well as phase separations, giving a rational underpinning to the design of catalysts with specific core-shell structures, enrichments, and nanodomain formation. Moving to more realistic and more challenging catalytic materials, specific sample preparation procedures have been developed on a case to case basis: the electrophoresis method, the encapsulation method, powder solidification, electrodeposition, the use of fusible materials, and even the synthesis on an APT coupon followed by encapsulation, implemented to study oxide-support catalysts. The advances in FIB instrumentation, electron-beam-assisted-deposition methods and site-specific sample preparation techniques greatly assisted the development of such procedures. Of course, these methods have advantages and drawbacks, especially regarding the incorporation of contaminants, the time required, and the formation of regular/irregular surfaces, and there is considerable potential for improvements to increase the reproducibility and accuracy of the resulting data.

Improved stability and decreased activity of iridium oxides towards the oxygen evolution reaction (OER) have been unveiled with a near-atomic-scale resolution by atom probe tomography, as well as the temporal evolution of species at the surface of iridium oxides, critical to better understand the composition/activity/stability relationships in electrocatalysis [203]. APT has also been used to better understand photocatalytic systems and the importance of the nanojunction and subsequent ion exchange between $\mathrm{Cd}$ chalcogenide and $\mathrm{ZnO}$ crystals [204]. Another striking demonstration is the use of isolated $\mathrm{Ni}$ atoms dispersed on graphene for the $\mathrm{CO}_{2}$ reduction reaction $\left(\mathrm{CO}_{2} \mathrm{RR}\right)$. It is indeed known that for obtaining a high selectivity during $\mathrm{CO}_{2} \mathrm{RR}$, catalysts with specific electronic structures are required [205]. Introducing transition metals into a known matrix could be used to tune the electronic properties of the metal [206], but also to pin the metal and avoid nucleation processes [207]. In this frame, Ni atoms embedded in graphene shells exhibit great catalytic $\mathrm{CO}_{2} \mathrm{RR}$ performance, and APT analysis provides a direct identification of the presence single Ni atoms [208], pushing the boundaries of resolution available by the APT technique.

Analysis of unsupported nanoparticles has demonstrated the importance of the thickness of the shell in core-shell structures for the catalytic activity as well as the effect that impurities can have on the final surface composition and morphology. Experiments on supported nanoparticles showed that APT can be used as a quality control tool to validate the purity, the size, the composition, the dispersion, and the expected structure of synthesized catalysts. These specimens also suffered from the issues of heterogeneous materials in APT, leading to trajectory overlaps and aberrations, and the problem of porous supports, since porosity is present on unsupported catalysts as powders or as nanoporous structures. For the latter, APT proved its relevance to study the synthesis of nanoporous materials with tuned ligament and pore sizes. Finally, coke formation leading to the deactivation of zeolites can be traced back to a non-uniform distribution of $\mathrm{Al}$ within the bulk, leading to different acidic properties, and the nanoscale changes in elemental distribution can be used to assess the activity and stability of zeolite catalysts.

Many of the results obtained by APT and presented in this review require the use of correlative microscopy and/or correlative tomography, whether it is to optimize the reconstruction parameters, 
or to gain complementary characterization data not available by APT. Taking all this into account, it can be concluded that atom probe tomography is a relevant and growing technique for the study of catalytic systems, and has the potential to further evolve into one of the most essential analytical tools in catalysis research.

Funding: This work was supported as part of the Integrated Mesoscale Architectures for Sustainable Catalysis-IMASC, an Energy Frontier Research Center funded by the U.S. Department of Energy, Office of Science, Basic Energy Sciences under Award \# DE-SC0012573.

Acknowledgments: C.B. acknowledges postdoctoral fellowships through the Belgian American Educational Foundation (BAEF), the Wallonie-Bruxelles International (Excellence grant WBI.WORLD), as well as the Fonds de la Recherche Scientifique (F.R.S.-FNRS). C.B. also thanks Luc Jacobs for fruitful discussions. D.C.B. and C.B. acknowledge the use of the Center for Nanoscale Systems (CNS), a member of the National Nanotechnology Coordinated Infrastructure Network (NNCI), which is supported by the National Science Foundation under NSF award no. 1541959.

Conflicts of Interest: The authors declare no conflict of interest. The funders had no role in the design of the study; in the collection, analyses, or interpretation of data; in the writing of the manuscript, or in the decision to publish the results.

\section{References}

1. Kaltner, W.; Lorenz, K.; Schillinger, B.; Jentys, A.; Lercher, J.A. Using tomography for exploring complex structured emission control catalysts. Catal. Lett. 2010, 134, 24-30. [CrossRef]

2. Devred, F.; Reinhart, G.; Iles, G.N.; van der Klugt, B.; Adkins, N.J.; Bakker, J.W.; Nieuwenhuys, B.E. Synchrotron X-ray microtomography of Raney-type nickel catalysts prepared by gas atomization: Effect of microstructure on catalytic performance. Catal. Today 2011, 163, 13-19. [CrossRef]

3. Goulas, K.A.; Dert, S.; Dietrich, P.; Johnson, G.R.; Grippo, A.; Wang, Y.C.; Gross, E. X-ray tomography measurements identify structure-reactivity correlations in catalysts for oxygenates coupling reactions. Catal. Today 2018. [CrossRef]

4. Sheppard, T.L.; Price, S.W.T.; Benzi, F.; Baier, S.; Klumpp, M.; Dittmeyer, R.; Schwieger, W.; Grunwaldt, J.-D. In situ multimodal 3D chemical imaging of a hierarchically structured core@shell catalyst. J. Am. Chem. Soc. 2017, 139, 7855-7863. [CrossRef]

5. Van Hoof, A.J.F.; Filot, I.A.W.; Friedrich, H.; Hensen, E.J.M. Reversible restructuring of silver particles during ethylene epoxidation. ACS Catal. 2018, 8, 11794-11800. [CrossRef] [PubMed]

6. Fam, Y.; Sheppard, T.L.; Diaz, A.; Scherer, T.; Holler, M.; Wang, W.; Wang, D.; Brenner, P.; Wittstock, A.; Grunwaldt, J.-D. Correlative multiscale 3D imaging of a hierarchical nanoporous gold catalyst by electron, ion and X-ray nanotomography. ChemCatChem 2018, 10, 2858-2867. [CrossRef]

7. Li, T.; Wu, H.; Ihli, J.; Ma, Z.; Krumeich, F.; Bomans, P.H.H.; Sommerdijk, N.A.J.M.; Friedrich, H.; Patterson, J.P.; van Bokhoven, J.A. Cryo-TEM and electron tomography reveal leaching-induced pore formation in ZSM-5 zeolite. J. Mater. Chem. A 2019, 7, 1442-1446. [CrossRef]

8. Barroo, C.; Bagot, P.A.J.; Smith, G.D.W.; Visart de Bocarmé, T. Investigating nano-structured catalysts at the atomic scale by field ion microscopy and atom probe tomography. In Atomically-Precise Methods for Synthesis of Solid Catalysts; Hermans, S., Visart de Bocarmé, T., Eds.; RSC Catalysis Series; The Royal Society of Chemistry: Cambridge, UK, 2015; pp. 248-295.

9. Müller, E. Field Ion Microscopy Principles and Applications; American Elsevier Pub.: Amsterdam, The Netherlands, 1969.

10. Miller, M.K.; Cerezo, A.; Hetherington, M.G.G.; Smith, G.D.W. Atom Probe Field Ion Microscopy; Clarendon Press: Oxford, UK, 1996.

11. Suchorski, Y.; Imbihl, R.; Medvedev, V.K. Compatibility of field emitter studies of oscillating surface reactions with single crystal measurements: Catalytic CO oxidation on Pt. Surf. Sci. 1998, 401, 392-399. [CrossRef]

12. Suchorski, Y.; Beben, J.; Imbihl, R.; James, E.W.; Liu, D.-J.; Evan, J.W. Fluctuations and critical phenomena in catalytic CO oxidation on nanoscale Pt facets. Phys. Rev. B 2001, 63, 165417. [CrossRef]

13. Suchorski, Y.; Drachsel, W.; Gorodetskii, V.V.; Medvedev, V.K.; Weiss, H. Lifted reconstruction as a feedback mechanism in the oscillating CO oxidation on Pt nanofacets: Microscopic evidences. Surf. Sci. 2006, 600, 1579-1585. [CrossRef] 
14. Visart de Bocarmé, T.; Bär, T.; Kruse, N. Field ion microscopy study of the structural changes in Rh crystals during the reaction of oxygen-hydrogen gas mixtures. Surf. Sci. 2000, 454-456, 320-325. [CrossRef]

15. Visart de Bocarmé, T.; Bär, T.; Kruse, N. In situ dynamic study of hydrogen oxidation on rhodium. Ultramicroscopy 2001, 89, 75-82. [CrossRef]

16. McEwen, J.-S.; Gaspard, P.; Visart de Bocarmé, T.; Kruse, N. Nanometric chemical clocks. Proc. Natl. Acad. Sci. USA 2009, 106, 3006-3010. [CrossRef] [PubMed]

17. Van Tol, M.F.H.; Gielbert, A.; Nieuwenhuys, B.E. Oscillatory behaviour of the reduction of $\mathrm{NO}$ by $\mathrm{H}_{2}$ over Rh. Catal. Lett. 1992, 16, 297-309. [CrossRef]

18. Cobden, P.D.; de Wolf, C.A.; Smirnov, M.Y.; Makeev, A.; Nieuwenhuys, B.E. Non-linear processes on Pt, $\mathrm{Rh}, \mathrm{Pd}, \mathrm{Ir}$ and Ru surfaces during the NO-hydrogen reactions. J. Mol. Catal. A Chem. 2000, 158, 115-128. [CrossRef]

19. Gorodetskii, V.V.; Elokhin, V.I.; Bakker, J.W.; Nieuwenhuys, B.E. Field electron and field ion microscopy studies of chemical wave propagation in oscillatory reactions on platinum group metals. Catal. Today 2005, 105, 183-205. [CrossRef]

20. Barroo, C.; De Decker, Y.; Visart de Bocarmé, T.; Kruse, N. Emergence of chemical oscillations from nanosized target patterns. Phys. Rev. Lett. 2016, 117, 144501. [CrossRef]

21. Barroo, C.; De Decker, Y.; Jacobs, L.; Visart de Bocarmé, T. Nonlinear behavior during $\mathrm{NO}_{2}$ hydrogenation on a nanosized Pt-Rh catalyst sample. Appl. Surf. Sci. 2017, 412, 564-570. [CrossRef]

22. Barroo, C.; De Decker, Y.; Visart de Bocarmé, $\mathrm{T}$. $\mathrm{NO}_{2}$ hydrogenation on Rh catalysts: Bifurcations and oscillations at the nanoscale. J. Phys. Chem. C 2017, 121, 17235-17243. [CrossRef]

23. Barroo, C.; Visart de Bocarmé, T.; De Decker, Y.; Kruse, N. Surface reactions investigated at the nanoscale by field emission techniques: Nonlinear dynamics of the catalytic hydrogenation of $\mathrm{NO}$ and $\mathrm{NO}_{2}$ over platinum crystallites. In Encyclopedia of Interfacial Chemistry: Surface Science and Electrochemistry, 1st ed.; Wandelt, K., Ed.; Elsevier: Amsterdam, The Netherlands, 2018; Volume 2.1, pp. 251-260.

24. Ahmad, M.; Tsong, T.T. Surface segregation and diffusion kinetics study of a PtIr alloy using the time of flight atom probe field ion microscope. Appl. Phys. Lett. 1984, 44, 40-42. [CrossRef]

25. Ng, Y.S.; Tsong, T.T.; McLane, S.B., Jr. Atom-probe FIM investigation of surface segregation in Ni-Cu, stainless steel 410 and Pt-Au alloys. Surf. Sci. 1979, 84, 31-53.

26. Tsong, T.T.; Ng, Y.S.; McLane, S.B., Jr. Surface segregation of a Pt-Au alloy: An atom probe field ion microscope investigation. J. Chem. Phys. 1980, 73, 1464-1468. [CrossRef]

27. Tsong, T.T.; Ren, D.M.; Ahmad, M. Atomic-layer by atomic-layer compositional depth profiling: Surface segregation and impurity cosegregation of Pt-Rh and Pt-Ru alloys. Phys. Rev. B 1988, 38, 7428-7435. [CrossRef] [PubMed]

28. Ahmad, M.; Tsong, T.T. Compositional variations in the near surface layers, an atom probe study of cosegregation of sulfur in Pt-Rh and Pt-Ir alloys. J. Chem. Phys. 1985, 83, 388-396. [CrossRef]

29. Hono, K.; Iwata, T.; Nakamura, M.; Pickering, H.W.; Kamiya, I.; Sakurai, T. Atom-probe study of the initial stage of selective oxidation of Ni from the Cu-Ni alloy system. Surf. Sci. 1991, 245, 132-149. [CrossRef]

30. Cocke, D.L.; Chuah, G.K.; Kruse, N.; Block, J.H. Copper oxidation and surface copper oxide stability investigated by pulsed field desorption mass spectrometry. Appl. Surf. Sci. 1995, 84, 153-161. [CrossRef]

31. Cocke, D.L.; Abend, G.; Block, J.H.; Kruse, N. Oxidation of ruthenium studied by pulsed field desorption mass spectrometry. Langmuir 1985, 1, 507-509. [CrossRef]

32. Tsong, T.T.; Ng, Y.S.; McLane, S.B., Jr. Surface segregation of NiCu alloy in nitrogen and oxygen: An atom probe field ion microscope study. J. Appl. Phys. 1980, 51, 6189-6191. [CrossRef]

33. Kellogg, G.L. Pulsed laser atom-probe study of the dissociation of CO on molybdenum. Surf. Sci. 1981, 111, 205-213. [CrossRef]

34. Hren, J.; Kellogg, G.L. Field-ion microscopy and atom-probe mass spectroscopy of sulfur on the (111) plane of nickel. Surf. Sci. 1984, 147, 349-355. [CrossRef]

35. Kruse, N.; Abend, G.; Block, J.H. Interaction of cyanogen with Pt single crystal surfaces, studied by pulsed field desorption mass spectrometry. Z. Phys. Chem. 1985, 144, 1-8. [CrossRef]

36. Block, J.H.; Kruse, N. Chemical surface reactions of $\mathrm{CO}$ on the atomic scale: Investigations by field ion microscopy and mass spectrometry. React. Kinet. Catal. Lett. 1987, 35, 11-20. [CrossRef]

37. Liang, D.B.; Abend, G.; Block, J.H. Formation of nickel subcarbonyls from nickel and carbon monoxide. Surf. Sci. 1983, 126, 392-396. [CrossRef] 
38. Chau, T.-D.; Visart de Bocarmé, T.; Kruse, N. Formation of $\mathrm{N}_{2} \mathrm{O}$ and $(\mathrm{NO})_{2}$ during $\mathrm{NO}$ adsorption on Au 3D crystals. Catal. Lett. 2004, 98, 85-97. [CrossRef]

39. Visart de Bocarmé, T.; Chau, T.-D.; Kruse, N. Dynamic interaction of $\mathrm{CO} / \mathrm{H}_{2} \mathrm{O}$ mixtures with gold nanocrystals: Real-time imaging and local probing. Surf. Sci. 2006, 600, 4205-4210. [CrossRef]

40. Lambeets, S.V.; Barroo, C.; Owczarek, S.; Jacobs, L.; Genty, E.; Gilis, N.; Kruse, N.; Visart de Bocarmé, T. Adsorption and hydrogenation of $\mathrm{CO}_{2}$ on Rh nanosized crystals: Demonstration of the role of interfacet oxygen spillover and comparative studies with $\mathrm{O}_{2}, \mathrm{~N}_{2} \mathrm{O}$, and CO. J. Phys. Chem. C 2017, 121, 16238-16249. [CrossRef]

41. Chuah, G.K.; Kruse, N.; Schmidt, W.A.; Block, J.H.; Abend, G. Methanol adsorption and decomposition on rhodium. J. Catal. 1989, 119, 342-353. [CrossRef]

42. Kruse, N. Surface reaction kinetics on the atomic scale: Studies by means of pulsed field desorption mass spectrometry. Mater. Sci. Eng. A 1999, 270, 75-82. [CrossRef]

43. Che, F.; Gray, J.T.; Ha, S.; Kruse, N.; Scott, S.L.; McEwen, J.-S. Elucidating the roles of electric fields in catalysis: A perspective. ACS Catal. 2018, 8, 5153-5174. [CrossRef]

44. Kellogg, G.L. The oxidation of rhodium field-emitter surfaces during CO oxidation reaction. J. Catal. 1985, 92, 167-172. [CrossRef]

45. Kellogg, G.L. Direct observations of surface chemical and structural changes resulting from the CO oxidation reaction on rhodium. J. Vac. Sci. Technol. A 1986, 4, 1419-1423. [CrossRef]

46. Kellogg, G.L. Initial stages of oxide formation on rhodium field emitters. Phys. Rev. Lett. 1985, 54, 82-85. [CrossRef] [PubMed]

47. Kruse, N. Nitric oxide interaction with Rh metal: Kinetics of elemental steps and reaction with carbon monoxide. J. Mol. Catal. A Chem. 2000, 163, 79-89. [CrossRef]

48. Kruse, N. Time resolved reaction studies on the atomic scale: NO and CO adsorption on stepped Rh surfaces. J. Vac. Sci. Technol. A 1990, 8, 3432-3436. [CrossRef]

49. Liu, W.; Bao, C.L.; Ren, D.M.; Tsong, T.T. Methanation on Rh surfaces at low pressure and low temperature: A pulsed-laser imaging atom-probe study. Surf. Sci. 1987, 180, 153-168. [CrossRef]

50. Bao, C.L.; Tsong, T.T. Methanation on Ir surfaces at low gas pressure and temperature. A study by pulsed-laser field desorption time-of-flight mass spectroscopy. Surf. Sci. 1988, 201, 371-384. [CrossRef]

51. Visart de Bocarmé, T.; Kruse, N. Field emission techniques for studying surface reactions: Applying them to $\mathrm{NO}-\mathrm{H}_{2}$ interaction with Pd tips. Ultramicroscopy 2011, 111, 376-380. [CrossRef]

52. Barroo, C.; Moors, M.; Visart de Bocarmé, T. Imaging and chemical probing catalytic processes using field emission techniques: Study of NO hydrogenation on Pd and Pd-Au catalysts. Catal. Sci. Technol. 2017, 7, 5249-5256. [CrossRef]

53. Visart de Bocarmé, T.; Beketov, G.; Kruse, N. Water formation from $\mathrm{O}_{2}$ and $\mathrm{H}_{2}$ on Rh tips: Studies by field ion microscopy and pulsed field desorption mass spectrometry. Surf. Interface Anal. 2004, 36, 522-527. [CrossRef]

54. Block, J.H.; Abend, G.; Kruse, N.; Weimer, J.J. Determination of reaction intermediates of heterogeneous catalytic reactions by field pulse desorption dedicated to Prof. John Happel on the occasion of his 80th birthday. Chem. Eng. Comm. 1989, 83, 103-109. [CrossRef]

55. Moors, M.; Visart de Bocarmé, T.; Kruse, N. Surface reaction kinetics studied with nanoscale lateral resolution. Catal. Today 2007, 124, 61-70. [CrossRef]

56. Moors, M.; Amara, H.; Visart de Bocarmé, T.; Bichara, C.; Ducastelle, F.; Kruse, N.; Charlier, J.-C. Early stages in the nucleation process of carbon nanotubes. ACS Nano 2009, 3, 511-516. [CrossRef] [PubMed]

57. Moors, M.; Visart de Bocarmé, T.; Kruse, N. $\mathrm{C}_{2} \mathrm{H}_{2}$ interaction with Ni nanocrystals: Towards a better understanding of carbon nanotubes nucleation in CVD synthesis. Ultramicroscopy 2009, 109, 381-384. [CrossRef] [PubMed]

58. Müller, E.W.; Panitz, J.A.; Brooks McLane, S. The atom-probe field ion microscope. Rev. Sci. Instrum. 1968, 39, 83-86. [CrossRef]

59. Gault, B.; Moody, M.P.; Cairney, J.M.; Ringer, S.P. Atom Probe Microscopy; Hull, H., Jagadish, C., Osgood, R.M., Jr., Parisi, J., Wang, Z.M., Eds.; Springer Series in Materials Science; Springer: New York, NY, USA, 2012; Volume 160.

60. Larson, D.J.; Prosa, T.J.; Ulfig, R.M.; Geiser, B.P.; Kelly, T.F. Local Electrode Atom Probe Tomography. A User's Guide; Springer: New York, NY, USA, 2013. 
61. Miller, M.K.; Forbes, R.G. Atom-Probe Tomography: The Local Electrode Atom Probe; Springer: New York, NY, USA, 2014.

62. Lefebvre-Ulrikson, W.; Vurpillot, F.; Sauvage, X. Atom Probe Tomography. Put Theory into Practice; Elsevier: Amsterdam, The Netherlands, 2016.

63. Ceguerra, A.V.; Breen, A.J.; Stephenson, L.T.; Felfer, P.J.; Araullo-Peters, V.J.; Liddicoat, P.V.; Cui, X.-Y.; Yao, L.; Haley, D.; Moody, M.P.; et al. The rise of computational techniques in atom probe microscopy. Curr. Opin. Solid State Mater. Sci. 2013, 17, 224-235. [CrossRef]

64. Larson, D.J.; Gault, B.; Geiser, B.P.; De Geuser, F.; Vurpillot, F. Atom probe tomography spatial reconstruction: Status and directions. Curr. Opin. Solid State Mater. Sci. 2013, 17, 236-247. [CrossRef]

65. Vurpillot, F.; Lefebvre, W.; Cairney, J.M.; Oberdorfer, C.; Geiser, B.P.; Rajan, K. Advanced volume reconstruction and data mining methods in atom probe tomography. MRS Bull. 2016, 41, 46-52. [CrossRef]

66. Vurpillot, F.; Parviainen, S.; Djurabekova, F.; Zanuttini, D.; Gervais, B. Simulation tools for atom probe tomography: A path for diagnosis and treatment of image degradation. Mater. Charact. 2018, 146, 336-346. [CrossRef]

67. Cui, X.-Y.; Ringer, S.P. On the nexus between atom probe microscopy and density functional theory simulations. Mater. Charact. 2018, 146, 347-358. [CrossRef]

68. Seidnam, D.N. Three-dimensional atom-probe tomography: Advances and applications. Annu. Rev. Mater. Res. 2007, 37, 127-158.

69. Kelly, T.F.; Larson, D.J.; Thompson, K.; Alvis, R.L.; Bunton, J.H.; Olson, J.D.; Gorman, B.P. Atom probe tomography of electronic materials. Annu. Rev. Mater. Res. 2007, 37, 681-727. [CrossRef]

70. Marquis, E.A.; Bachhav, M.; Chen, Y.; Dong, Y.; Gordon, L.M.; McFarland, A. On the current role of atom probe tomography in materials characterization and materials science. Curr. Opin. Solid State Mater. Sci. 2013, 17, 217-223. [CrossRef]

71. Larson, D.J.; Prosa, T.J.; Perea, D.E.; Inoue, K.; Mangelinck, D. Atom probe tomography of nanoscale electronic materials. MRS Bull. 2016, 41, 30-34. [CrossRef]

72. Stiller, K.; Thuvander, M.; Povstugar, I.; Choi, P.P.; Andrén, H.-O. Atom probe tomography of interfaces in ceramic films and oxide scales. MRS Bull. 2016, 41, 35-39. [CrossRef]

73. Blum, T.B.; Darling, J.R.; Kelly, T.F.; Larson, D.J.; Moser, D.E.; Perez-Huerta, A.; Prosa, T.J.; Reddy, S.M.; Reinhard, D.A.; Saxey, D.W.; et al. Best practices for reporting atom probe analysis of geological materials. In Microstructural Geochronology: Planetary Records down to Atom Scale; Moser, D.E., Corfu, F., Darling, J.R., Reddy, S.M., Tait, K., Eds.; Geophysical Monograph Series; American Geophysical Union and John Wiley \& Sons, Inc.: Hoboken, NJ, USA, 2018.

74. Miller, M.K.; Forbes, R.G. Atom probe tomography. Mater. Charact. 2009, 60, 461-469. [CrossRef]

75. Miller, M.K.; Russell, K.F.; Thompson, K.; Alvis, R.; Larson, D.J. Review of atom probe FIB-based specimen preparation methods. Microsc. Microanal. 2007, 13, 428-436. [CrossRef] [PubMed]

76. Devaraj, A.; Perea, D.E.; Liu, J.; Gordon, L.M.; Prosa, T.J.; Parikh, P.; Diercks, D.R.; Meher, S.; Kolli, R.P.; Meng, Y.S.; et al. Three-dimensional nanoscale characterisation of materials by atom probe tomography. Int. Mater. Rev. 2017, 63, 68-101. [CrossRef]

77. Roussel, M.; Talbot, E.; Gourbilleau, F.; Pareige, P. Atomic characterization of Si nanoclusters embedded in $\mathrm{SiO}_{2}$ by atom probe tomography. Nanoscale Res. Lett. 2011, 6, 164. [CrossRef]

78. Felfer, P.J.; Alam, T.; Ringer, S.P.; Cairney, J.M. A reproducible method for damage-free site-specific preparation of atom probe tips from interfaces. Microsc. Res. Tech. 2012, 75, 484-491. [CrossRef] [PubMed]

79. Prosa, T.J.; Larson, D.J. Modern focused-ion-beam-based site-specific specimen preparation for atom probe tomography. Microsc. Microanal. 2017, 23, 194-209. [CrossRef]

80. Schreiber, D.K.; Perea, D.E.; Ryan, J.V.; Evans, J.E.; Vienna, J.D. A method for site-specific and cryogenic specimen fabrication of liquid/solid interfaces for atom probe tomography. Ultramicroscopy 2018, 194, 89-99. [CrossRef] [PubMed]

81. Baik, S.-I.; Isheim, D.; Seidman, D.N. Systematic approaches for targeting an atom-probe tomography sample fabricated in a thin TEM specimen: Correlative structural, chemical and 3-D reconstruction analyses. Ultramicroscopy 2018, 184, 284-292. [CrossRef] [PubMed]

82. Mouton, I.; Katnagallu, S.; Makineni, S.K.; Cojocaru-Mirédin, O.; Schwarz, T.; Stephenson, L.T.; Raabe, D.; Gault, B. Calibration of atom probe tomography reconstructions through correlation with electron micrographs. Microsc. Microanal. 2019, 25, 301-308. [CrossRef] [PubMed] 
83. Babinsky, K.; De Kloe, R.; Clemens, H.; Primig, S. A novel approach for site-specific atom probe specimen preparation by focused ion beam and transmission electron backscatter diffraction. Ultramicroscopy 2014, 144, 9-18. [CrossRef] [PubMed]

84. Rice, K.P.; Chen, Y.; Prosa, T.J.; Larson, D.J. Implementing transmission electron backscatter diffraction for atom probe tomography. Microsc. Microanal. 2016, 22, 583-588. [CrossRef] [PubMed]

85. Bagot, P.A.J.; Visart de Bocarmé, T.; Cerezo, A.; Smith, G.D.W. 3D atom probe study of gas adsorption and reaction on alloy catalyst surfaces I: Instrumentation. Surf. Sci. 2006, 600, 3028-3035. [CrossRef]

86. Dumpala, S.; Broderick, S.R.; Bagot, P.A.J.; Rajan, K. An integrated high temperature environmental cell for atom probe tomography studies of gas-surface reactions: Instrumentation and results. Ultramicroscopy 2014, 141, 16-21. [CrossRef]

87. Haley, D.; McCarroll, I.; Bagot, P.A.J.; Cairney, J.M.; Moody, M.P. A gas-phase reaction cell for modern atom probe systems. Microsc. Microanal. 2019, 25, 410-417. [CrossRef]

88. Bagot, P.A.J.; Cerezo, A.; Smith, G.D.W.; Visart de Bocarmé, T.; Godfrey, T.J. Automobile exhaust catalysis at the atomic scale: Atom-probe investigations on platinum alloys. Surf. Interface Anal. 2007, 39, 172-177. [CrossRef]

89. Bagot, P.A.J.; Cerezo, A.; Smith, G.D.W. 3D atom probe study of gas adsorption and reaction on alloy catalyst surfaces II: Results on Pt and Pt-Rh. Surf. Sci. 2007, 601, 2245-2255. [CrossRef]

90. Bagot, P.A.J.; Cerezo, A.; Smith, G.D.W. 3D atom probe study of gas adsorption and reaction on alloy catalyst surfaces III: Ternary alloys—NO on Pt-Rh-Ru and Pt-Rh-Ir. Surf. Sci. 2008, 602, 1381-1391. [CrossRef]

91. Visart de Bocarmé, T.; Moors, M.; Kruse, N.; Atanasov, I.S.; Hou, M.; Cerezo, A.; Smith, G.D.W. Surface segregation of Au-Pd alloys in UHV and reactive environments: Quantification by a catalytic atom probe. Ultramicroscopy 2009, 109, 619-624. [CrossRef] [PubMed]

92. Gilis, N.; Jacobs, L.; Barroo, C.; Visart de Bocarmé, T. Surface segregation in Au-Ag alloys investigated by atom probe tomography. Top. Catal. 2018, 61, 1437-1448. [CrossRef]

93. Moody, M.P.; Vella, A.; Gerstl, S.S.A.; Bagot, P.A.J. Advances in atom probe tomography instrumentation: Implications for materials research. MRS Bull. 2016, 41, 40-45. [CrossRef]

94. Perea, D.E.; Gerstl, S.S.A.; Chin, J.; Hirschi, B.; Evans, J.E. An environmental transfer hub for multimodal atom probe tomography. Adv. Struct. Chem. Imaging 2017, 3, 12. [CrossRef] [PubMed]

95. Stephenson, L.T.; Szczepaniak, A.; Mouton, I.; Rusitzka, K.A.K.; Breen, A.J.; Tezins, U.; Sturm, A.; Vogel, D.; Chang, Y.; Kontis, P.; et al. The Laplace Project: An integrated suite for preparing and transferring atom probe samples under cryogenic and UHV conditions. PLoS ONE 2018, 13, e0209211. [CrossRef] [PubMed]

96. Bagot, P.A.J. Fundamental surface science studies of automobile exhaust catalysis. Mater. Sci. Technol. 2004, 20, 679-694. [CrossRef]

97. Kruse, N.; Visart de Bocarmé, T. Heterogeneous catalysis and high electric fields. In Handbook of Heterogeneous Catalysis, 2nd ed.; Ertl, G., Knözinger, H., Schüth, F., Weitkamp, J., Eds.; Wiley-VCH: Weinheim, Germany, 2008; pp. 870-895.

98. Bagot, P.A.J.; Kreuzer, H.J.; Cerezo, A.; Smith, G.D.W. A model for oxidation-driven surface segregation and transport on Pt-alloys studied by atom probe tomography. Surf. Sci. 2011, 605, 1544-1549. [CrossRef]

99. Nga, N.L.T.; Potvin, C.; Djéga-Mariadassou, G.; Delannoy, L.; Louis, C. Catalytic reduction of nitrogen monoxide by propene in the presence of excess oxygen over gold-based ceria catalyst. Top. Catal. 2007, 42-43, 91-94. [CrossRef]

100. Arve, K.; Adam, J.; Simakova, O.; Čapek, L.; Eränen, K.; Murzin, D.Y. Selective catalytic reduction of NOx over nano-sized gold catalysts supported on alumina and titania and over bimetallic gold-silver catalysts supported on alumina. Top. Catal. 2009, 52, 1762-1765. [CrossRef]

101. More, P.M.; Nguyen, D.L.; Granger, P.; Dujardin, C.; Dongare, M.K.; Umbarkar, S.B. Activation by pretreatment of $\mathrm{Ag}-\mathrm{Au} / \mathrm{Al}_{2} \mathrm{O}_{3}$ bimetallic catalyst to improve low temperature HC-SCR of NOx for lean burn engine exhaust. Appl. Catal. B Environ. 2015, 174, 145-156. [CrossRef]

102. Genty, E.; Jacobs, L.; Visart de Bocarmé, T.; Barroo, C. Dynamic processes on gold-based catalysts followed by environmental microscopies. Catalysts 2017, 7, 134. [CrossRef]

103. Hilaire, L.; Légaré, P.; Holl, Y.; Maire, G. Interaction of oxygen and hydrogen with Pd-Au alloys: An AES and XPS study. Surf. Sci. 1981, 103, 125-140. [CrossRef]

104. Zugic, B.; Wang, L.; Heine, C.; Zakharov, D.N.; Lechner, B.A.J.; Stach, E.A.; Biener, J.; Salmeron, M.; Madix, R.J.; Friend, C.M. Dynamic restructuring drives catalytic activity on nanoporous gold-Silver alloy catalysts. Nat. Mater. 2017, 16, 558-564. [CrossRef] [PubMed] 
105. Biener, J.; Biener, M.M.; Madix, R.J.; Friend, C.M. Nanoporous gold: Understanding the origin of the reactivity of a 21st century catalyst made by pre-columbian technology. ACS Catal. 2015, 5, 6263-6270. [CrossRef]

106. Personick, M.L.; Zugic, B.; Biener, M.M.; Biener, J.; Madix, R.J.; Friend, C.M. Ozone-activated nanoporous gold: A stable and storable material for catalytic oxidation. ACS Catal. 2015, 5, 4237-4241. [CrossRef]

107. Wang, L.-C.; Personick, M.L.; Karakalos, S.; Fushimi, R.; Friend, C.M.; Madix, R.J. Active sites for methanol partial oxidation on nanoporous gold catalysts. J. Catal. 2016, 344, 778-783. [CrossRef]

108. Jacobs, L.; Barroo, C.; Gilis, N.; Lambeets, S.V.; Genty, E.; Visart de Bocarmé, T. Structure reactivity relationships during $\mathrm{N}_{2} \mathrm{O}$ hydrogenation avec Au-Ag alloys: A study by field emission techniques. Appl. Surf. Sci. 2018, 435, 914-919. [CrossRef]

109. Guisbiers, G.; Mendoza-Cruz, R.; Bazán-Díaz, L.; Velázquez-Salazar, J.J.; Mendoza-Perez, R.; Robledo-Torres, J.A.; Rodriguez-Lopez, J.-L.; Montejano-Carrizales, J.M.; Whetten, R.L.; José-Yacamán, M. Electrum, the gold-silver alloy, from the bulk scale to the nanoscale: Synthesis, properties, and segregation rules. ACS Nano 2016, 10, 188-198. [CrossRef]

110. Gong, H.R. Electronic structures and related properties of Ag-Au bulks and surfaces. Mater. Chem. Phys. 2010, 123, 326-330. [CrossRef]

111. Li, T.; Marquis, E.A.; Bagot, P.A.J.; Tsang, S.C.; Smith, G.D.W. Characterization of oxidation and reduction of a platinum-rhodium alloy by atom-probe tomography. Catal. Today 2011, 175, 552-557. [CrossRef]

112. Li, T.; Bagot, P.A.J.; Marquis, E.A.; Edman Tsang, S.C.; Smith, G.D.W. Characterization of oxidation and reduction of a palladium-rhodium alloy by atom-probe tomography. J. Phys. Chem. C 2012, 116, 4760-4766. [CrossRef]

113. Li, T.; Bagot, P.A.J.; Marquis, E.A.; Edman Tsang, S.C.; Smith, G.D.W. Atomic engineering of platinum alloy surfaces. Ultramicroscopy 2013, 132, 205-211. [CrossRef] [PubMed]

114. Li, T.; Bagot, P.A.J.; Marquis, E.A.; Edman Tsang, S.C.; Smith, G.D.W. Characterization of oxidation and reduction of $\mathrm{Pt}-\mathrm{Ru}$ and $\mathrm{Pt}-\mathrm{Rh}-\mathrm{Ru}$ alloys by atom probe tomography and comparison with $\mathrm{Pt}-\mathrm{Rh}$. J. Phys. Chem. C 2012, 116, 17633-17640. [CrossRef]

115. Morita, M.; Karasawa, M.; Asaka, T.; Owari, M. The analysis of metal catalyst nanoparticle by atom probe tomography. E-J. Surf. Sci. Nanotech. 2014, 2, 145-148. [CrossRef]

116. Bagot, P.A.J.; Kruska, K.; Haley, D.; Carrier, X.; Marceau, E.; Moody, M.P.; Smith, G.D.W. Oxidation and surface segregation of a Pt-Pd-Rh alloy catalyst. J. Phys. Chem. C 2014, 118, 26130-26138. [CrossRef]

117. Van den Berg, A.W.C.; Arean, C.O. Materials for hydrogen storage: Current research trends and perspectives. Chem. Commun. 2008, 668-681. [CrossRef]

118. Loges, B.; Boddien, A.; Gartner, F.; Junge, H.; Beller, M. Catalytic generation of hydrogen from formic acid and its derivatives: Useful hydrogen storage materials. Top. Catal. 2010, 53, 902-914. [CrossRef]

119. Larsen, R.; Ha, S.; Zakzeski, J.; Masel, R.I. Unusually active palladium-based catalysts for the electrooxidation of formic acid. J. Power Sources 2006, 157, 78-84. [CrossRef]

120. Tedsree, K.; Li, T.; Jones, S.; Chan, C.W.A.; Yu, K.M.K.; Bagot, P.A.J.; Marquis, E.A.; Smith, G.D.W.; Tsang, S.C.E. Hydrogen production from formic acid decomposition at room temperature using a Ag-Pd core-shell nanocatalyst. Nat. Nanotechnol. 2011, 6, 302-307. [CrossRef]

121. Li, T.; Bagot, P.A.J.; Christian, E.; Theobald, B.R.C.; Sharman, J.D.B.; Ozkaya, D.; Moody, M.P.; Edman Tsang, S.C.; Smith, G.D.W. Atomic imaging of carbon-supported Pt, Pt/Co, and Ir@Pt nanocatalysts by atom-probe tomography. ACS Catal. 2014, 4, 695-702. [CrossRef]

122. Yu, K.M.K.; Tong, W.; West, A.; Cheung, K.; Li, T.; Smith, G.D.W.; Guo, Y.; Tsang, S.C.E. Non-syngas direct steam reforming of methanol to hydrogen and carbon dioxide at low temperature. Nat. Commun. 2012, 3, 1230. [CrossRef] [PubMed]

123. Felfer, P.; Li, T.; Eder, K.; Galinski, H.; Magyar, A.P.; Bell, D.C.; Smith, G.D.W.; Kruse, N.; Ringer, S.P.; Cairney, J.M. New approaches to nanoparticle sample fabrication for atom probe tomography. Ultramicroscopy 2015, 159, 413-419. [CrossRef] [PubMed]

124. Felfer, P.; Benndorf, P.; Masters, A.; Maschmeyer, T.; Cairney, J.M. Revealing the distribution of the atoms within individual bimetallic catalyst nanoparticles. Angew. Chem. Int. Ed. 2014, 53, 11190-11193. [CrossRef] [PubMed]

125. Liu, X.; Wang, A.; Yang, X.; Zhang, T.; Mou, C.-Y.; Su, D.-S.; Li, J. Synthesis of thermally stable and highly active bimetallic Au-Ag nanoparticles on Inert supports. Chem. Mater. 2009, 21, 410-418. [CrossRef] 
126. Turkevich, J.; Stevenson, P.C.; Hillier, J. A study of the nucleation and growth processes in the synthesis of colloidal gold. Discuss. Faraday Soc. 1951, 11, 55-75. [CrossRef]

127. Yang, Q.; Joyce, D.E.; Saranu, S.; Hughes, G.M.; Varambhia, A.; Moody, M.P.; Bagot, P.A.J. A combined approach for deposition and characterization of atomically engineered catalyst nanoparticles. $m$ 2015, 1 , 125-131. [CrossRef]

128. Castro, T.; Li, Y.Z.; Reifenberger, R.; Choi, E.; Park, S.B.; Andres, R.P. Studies of individual nanometer-sized metallic clusters using scanning tunneling microscopy, field emission, and field ion microscopy. J. Vac. Sci. Technol. A 1989, 7, 2845-2849. [CrossRef]

129. Lovall, D.; Buss, M.; Andres, R.P.; Reifenberger, R. Resolving the atomic structure of supported nanometer-sized Au clusters. Phys. Rev. B 1998, 58, 889-896. [CrossRef]

130. Castro, T.; Reifenberger, R.; Choi, E.; Andres, R.P. A field emission technique to measure the melting temperature of individual nanometer-sized clusters. Surf. Sci. 1990, 234, 43-52. [CrossRef]

131. Sun, Z.; Hazut, O.; Yerushalmi, R.; Lauhon, L.J.; Seidman, D.N. Criteria and considerations for preparing atom-probe tomography specimens of nanomaterials utilizing an encapsulation methodology. Ultramicroscopy 2018, 184, 225-233. [CrossRef] [PubMed]

132. Larson, D.J.; Giddings, A.D.; Wu, Y.; Verheijen, M.A.; Prosa, T.J.; Roozeboom, F.; Rice, K.P.; Kessels, W.M.M.; Geiser, B.P.; Kelly, T.F. Encapsulation method for atom probe tomography analysis of nanoparticles. Ultramicroscopy 2015, 159, 420-426. [CrossRef] [PubMed]

133. Kim, S.-H.; Lee, J.Y.; Ahn, J.-P.; Choi, P.-P. Fabrication of atom probe tomography specimens from nanoparticles using a fusible Bi-In-Sn alloy as an embedding medium. Microsc. Microanal. 2019, 25, 438-446. [CrossRef] [PubMed]

134. Kim, S.-H.; Kang, P.W.; Park, O.O.; Seol, J.-B.; Ahn, J.-P.; Lee, J.Y.; Choi, P.-P. A new method for mapping the three-dimensional atomic distribution within nanoparticles by atom probe tomography (APT). Ultramicroscopy 2018, 190, 30-38. [CrossRef] [PubMed]

135. Hansen, T.W.; Wagner, J.B. Environmental transmission electron microscopy in an aberration-corrected environment. Microsc. Microanal. 2012, 18, 684-690. [CrossRef] [PubMed]

136. Hansen, T.W.; Wagner, J.B. Catalysts under controlled atmospheres in the transmission electron microscope. ACS Catal. 2014, 4, 1673-1685. [CrossRef]

137. Visart de Bocarmé, T.; Chau, T.-D.; Kruse, N. The interaction of $\mathrm{CO}-\mathrm{O}_{2}$ gas mixtures with Au tips: In situ imaging and local chemical probing. Surf. Interface Anal. 2007, 39, 166-171. [CrossRef]

138. Chen, M.S.; Goodman, D.W. The structure of catalytically active Au on titania. Science 2004, 306, $252-255$. [CrossRef]

139. Landman, U.; Yoon, B.; Zhang, C.; Heiz, U.; Arenz, M. Factors in gold nanocatalysis: Oxidation of CO in the non-scalable size regime. Top. Catal. 2007, 44, 145-158. [CrossRef]

140. Aguilar-Guerrero, V.; Gates, B.C. Kinetics of $\mathrm{CO}$ oxidation catalyzed by highly dispersed $\mathrm{CeO}_{2}$-supported gold. J. Catal. 2008, 260, 351-357. [CrossRef]

141. Fujitani, T.; Nakamura, I. Mechanism and active sites of the oxidation of $\mathrm{CO}$ over $\mathrm{Au} / \mathrm{TiO}$. Angew. Chem. Int. Ed. 2011, 50, 10144-10147. [CrossRef] [PubMed]

142. Uchiyama, T.; Yoshida, H.; Kamiuchi, N. Correlation of catalytic activity with the morphology change of supported Au nanoparticles in gas. Surf. Sci. 2017, 659, 16-19. [CrossRef]

143. McCaroll, I.; Scherrer, B.; Felfer, P.; Moody, M.P.; Cairney, J.M. Interpreting atom probe data from oxide-metal interfaces. Microsc. Microanal. 2018, 24, 342-349. [CrossRef] [PubMed]

144. Bachhav, M.; Pawar, G.; Vurpillot, F.; Danoix, R.; Danoix, F.; Hannoyer, B.; Dong, Y.; Marquis, E. Interpreting the presence of an additional oxide layer in analysis of metal oxides-metal interfaces in atom probe tomography. J. Phys. Chem. C 2019, 123, 1313-1319. [CrossRef]

145. Kolli, R.P. Atom probe tomography: A review of correlative analysis of interfaces and precipitates in metals and alloys. JOM 2018, 70, 1725-1735. [CrossRef]

146. Satyanarayana, V.N.T.K.; Shutthanandan, V.; Prosa, T.J.; Adusumilli, P.; Arey, B.; Buxbaum, A.; Wang, Y.C.; Tessner, T.; Ulfig, R.; Wang, C.M.; et al. Three-dimensional chemical imaging of embedded nanoparticles using atom probe tomography. Nanotechnology 2012, 23, 215704.

147. Vilayurganapathy, S.; Devaraj, A.; Colby, R.; Pandey, A.; Varga, T.; Shutthanandan, V.; Manandhar, S.; El-Khoury, P.Z.; Kayani, A.; Hess, W.P.; et al. Subsurface synthesis and characterization of Ag nanoparticles embedded in MgO. Nanotechnology 2013, 24, 095707. [CrossRef] [PubMed] 
148. Wang, C.M.; Shutthanandan, V.; Zhang, Y.; Thevuthasan, S. Atomic resolution imaging of Au nanocluster dispersed in $\mathrm{TiO}_{2}, \mathrm{SrTiO}_{3}$, and MgO. J. Am. Ceram. Soc. 2005, 88, 3184-3191. [CrossRef]

149. Devaraj, A.; Colby, R.; Shutthanandan, V.; Subramanian, V.; Wang, C.M.; Perea, D.E.; Thevuthasan, S. Characterization of embedded metallic nanoparticles in oxides by cross-coupling aberration-corrected STEM and atom probe tomography. Microsc. Microanal. 2012, 18, 912-913. [CrossRef]

150. Devaraj, A.; Colby, R.; Vurpillot, F.; Thevuthasan, S. Understanding atom probe tomography of oxide-supported metal nanoparticles by correlation with atomic-resolution electron microscopy and field evaporation simulation. J. Phys. Chem. Lett. 2014, 5, 1361-1367. [CrossRef]

151. Shinde, D.; Arnoldi, L.; Devaraj, A.; Vella, A. Laser-material interaction during atom probe tomography of oxides with embedded metal nanoparticles. J. Appl. Phys. 2016, 120, 164308. [CrossRef]

152. Kwak, C.; Park, T.J.; Suh, D.J. Effects of sodium addition on the performance of $\mathrm{PtCo} / \mathrm{Al}_{2} \mathrm{O}_{3}$ catalysts for preferential oxidation of carbon monoxide from hydrogen-rich fuels. Appl. Catal. A 2005, 278, 181-186. [CrossRef]

153. Barroo, C.; Akey, A.J.; Shan, J.; Flytzani-Stephanopoulos, M.; Bell, D.C. Sample preparation and analysis of aggregated 'single atom alloy' nanoparticles by atom probe tomography. Microsc. Microanal. 2017, 23, 1906-1907. [CrossRef]

154. Choi, P.-P.; Kwon, Y.-S.; Kim, J.-S.; Al-Kassab, T. Transmission electron microscopy and atom probe specimen preparation from mechanically alloyed powder using the focused ion-beam lift-out technique. J. Electron. Microsc. 2007, 56, 43-49. [CrossRef] [PubMed]

155. Choi, P.-P.; Al-Kassab, T.; Kwon, Y.-S.; Kim, J.-S.; Kirchheim, R. Application of focused ion beam to atom probe tomography specimen preparation from mechanically alloyed powders. Microsc. Microanal. 2007, 13, 347-353. [CrossRef] [PubMed]

156. Mridha, S.; Jaeger, D.L.; Arora, H.S.; Banerjee, R.; Mukherjee, S. Atomic distribution in catalytic amorphous metals. J. Nanomater. 2015, 25, 632138. [CrossRef]

157. Larde, R.; Bran, J.; Jean, M.; Le Breton, J.M. Nanoscale characterization of powder materials by atom probe tomography. Powder Technol. 2011, 208, 260-265. [CrossRef]

158. Wu, F.; Bellon, P.; Melmed, A.J.; Lusby, T.A. Forced mixing and nanoscale decomposition in ball-milled Cu-Ag characterized by APFIM. Acta Mater. 2001, 49, 453-461. [CrossRef]

159. Wu, F.; Bellon, P.; Lau, M.L.; Lavernia, E.J.; Lusby, T.A.; Melmed, A.J. A new approach to preparing tips for atom probe field ion microscopy from powder materials. Mater. Sci. Eng. A 2002, 327, 20-23. [CrossRef]

160. Wu, F.; Isheim, D.; Bellon, P.; Seidman, D.N. Nanocomposites stabilized by elevated-temperature ball milling of $\mathrm{Ag}_{50} \mathrm{Cu}_{50}$ powders: An atom probe tomographic study. Acta Mater. 2006, 54, 2605-2613. [CrossRef]

161. Bell, D.C.; Magyar, A.P.; Graham, A.C.; Baram, M. Microencapsulation method for atom probe analysis of powders. Microsc. Microanal. 2013, 19, 954-955. [CrossRef]

162. Xiang, Y.; Chitry, V.; Liddicoat, P.; Felfer, P.; Cairney, J.; Ringer, S.; Kruse, N. Long-chain terminal alcohols through catalytic CO hydrogenation. J. Am. Chem. Soc. 2013, 135, 7114-7117. [CrossRef] [PubMed]

163. Schweicher, J.; Bundhoo, A.; Kruse, N. Hydrocarbon chain lengthening in catalytic CO hydrogenation: Evidence for a CO-insertion mechanism. J. Am. Chem. Soc. 2012, 134, 16135-16138. [CrossRef] [PubMed]

164. Kuang, T.; Lyu, S.; Liu, S.; Zhang, Y.; Li, J.; Wang, G.; Wang, L. Controlled synthesis of cobalt nanocrystals on the carbon spheres for enhancing Fischer-Tropsch synthesis performance. J. Energy Chem. 2019, 33, 67-73. [CrossRef]

165. Xiang, Y.; Kruse, N. Tuning the catalytic CO hydrogenation to straight- and long-chain aldehydes/alcohols and olefins/paraffins. Nat. Commun. 2016, 7, 13058. [CrossRef] [PubMed]

166. Voss, J.M.; Xiang, Y.; Collinge, G.; Perea, D.E.; Kovarik, L.; McEwen, J.-S.; Kruse, N. Characterization of $\mathrm{CoCu}$ - and CoMn-based catalysts for the Fischer-Tropsch reaction toward chain-lengthened oxygenates. Top. Catal. 2018, 61, 1016-1023. [CrossRef]

167. Biener, J.; Wittstock, A.; Baumann, T.F.; Weissmüller, J.; Bäumer, M.; Hamza, A.V. Surface chemistry in nanoscale materials. Materials 2009, 2, 2404-2428. [CrossRef]

168. Falcucci, G.; Succi, S.; Montessori, A.; Melchionna, S.; Prestininzi, P.; Barroo, C.; Bell, D.C.; Biener, M.M.; Biener, J.; Zugic, B.; et al. Mapping reactive flow patterns in monolithic nanoporous catalysts. Microfluids Nanofluid. 2016, 20, 105. [CrossRef]

169. Fujita, T.; Guan, P.; McKenna, K.; Lang, X.; Hirata, A.; Zhang, L.; Tokunaga, T.; Arai, S.; Yamamoto, Y.; Tanaka, N.; et al. Atomic origins of the high catalytic activity of nanoporous gold. Nat. Mater. 2012, 11, 775-780. [CrossRef] 
170. Juarez, T.; Biener, J.; Weissmüller, J.; Hodge, A.M. Nanoporous metals with structural hierarchy: A review. Adv. Eng. Mater. 2017, 19, 1700389. [CrossRef]

171. Barroo, C.; Montemore, M.M.; Janvelyan, N.; Zugic, B.; Akey, A.J.; Magyar, A.P.; Ye, J.; Kaxiras, E.; Biener, J.; Bell, D.C. Macroscopic 3D nanoporosity formation by dry oxidation of AgAu alloys. J. Phys. Chem. C 2017, 121, 5115-5122. [CrossRef]

172. Pfeiffer, B.; Erichsen, T.; Epler, E.; Volkert, C.A.; Trompenaars, P.; Nowak, C. Characterization of nanoporous materials with atom probe tomography. Microsc. Microanal. 2015, 21, 557-563. [CrossRef] [PubMed]

173. Barroo, C.; Magyar, A.P.; Bell, D.C. Catalysis and atom probe tomography: Recent progresses and future developments towards the analysis of nanoporous samples. Microsc. Microanal. 2015, 21, 855-856. [CrossRef]

174. Barroo, C.; Janvelyan, N.; Zugic, B.; Magyar, A.P.; Akey, A.J.; Biener, J.; Friend, C.M.; Bell, D.C. Surface modifications during a catalytic reaction: A combined APT and FIB/SEM analysis of surface segregation. Microsc. Microanal. 2016, 22, 356-357. [CrossRef]

175. El-Zoka, A.A.; Langelier, B.; Botton, G.A.; Newman, R.C. Enhanced analysis of nanoporous gold by atom probe tomography. Mater. Charact. 2017, 128, 269-277. [CrossRef]

176. El-Zoka, A.A.; Langelier, B.; Korinek, A.; Botton, G.A.; Newman, R.C. Advances in nanoscale characterization of refined nanoporous gold. Electrochim. Acta 2018, 283, 611-618. [CrossRef]

177. Herino, R.; Jan, P.; Bomchil, G. Nickel plating on porous silicon. J. Electrochem. Soc. 1985, 132, $2513-2514$. [CrossRef]

178. Tzaneva, B.R.; Naydenov, A.I.; Todorova, S.Z.; Videkov, V.H.; Milusheva, V.S.; Stefanov, P.K. Cobalt electrodeposition in nanoporous anodic aluminium oxide for application as catalyst for methane combustion. Electrochim. Acta 2016, 191, 192-199. [CrossRef]

179. Hakamada, M.; Hirashima, F.; Takahashi, M.; Nakazawa, T.; Mabuchi, M. Large-strain induced magnetic properties of Co electrodeposited on nanoporous Au. J. Appl. Phys. 2011, 109, 084315. [CrossRef]

180. Mouton, I.; Printemps, T.; Grenier, A.; Gambacorti, N.; Pinna, E.; Tiddia, M.; Vacca, A.; Mula, G. Toward an accurate quantification in atom probe tomography reconstruction by correlative electron tomography on nanoporous materials. Ultramicroscopy 2017, 182, 112-117. [CrossRef]

181. Jin, H.; Wang, X.; Parida, S.; Wang, K.; Seo, M.; Weissmuller, J. Nanoporous Au-Pt alloys as large strain electrochemical actuators. Nano Lett. 2010, 10, 187-194. [CrossRef]

182. Lia, D.; Meng, F.; Wang, H.; Jiang, X.; Zhu, Y. Nanoporous AuPt alloy with low Pt content: A remarkable electrocatalyst with enhanced activity towards formic acid electrooxidation. Electrochim. Acta 2016, 190, 852-861. [CrossRef]

183. El-Zoka, A.A.; Langelier, B.; Korinek, A.; Botton, G.A.; Newman, R.C. Nanoscale mechanism of the stabilization of nanoporous gold by alloyed platinum. Nanoscale 2018, 10, 4904-4912. [CrossRef] [PubMed]

184. Khan, W.; Jia, X.; Wu, Z.; Choi, J.; Yip, A.C.K. Incorporating hierarchy into conventional zeolites for catalytic biomass conversions: A review. Catalysts 2019, 9, 127. [CrossRef]

185. Shamzhy, M.; Opanasenko, M.; Concepción, P.; Martínez, A. New trends in tailoring active sites in zeolite-based catalysts. Chem. Soc. Rev. 2019, 48, 1095-1149. [CrossRef] [PubMed]

186. Vogt, E.T.C.; Whiting, G.T.; Dutta Chowdhury, A.; Weckhuysen, B.M. Zeolites and zeotypes for oil and gas conversion. Adv. Catal. 2015, 58, 143-314.

187. Beale, A.M.; Gao, F.; Lezcano-Gonzalez, I.; Peden, C.H.F.; Szanyi, J. Recent advances in automotive catalysis for $\mathrm{NO}_{x}$ emission control by small-pore microporous materials. Chem. Soc. Rev. 2015, 44, 7371-7405. [CrossRef]

188. Schmidt, J.E.; Peng, L.; Poplawsky, J.D.; Weckhuysen, B.M. Nanoscale chemical imaging of zeolites using atom probe tomography. Angew. Chem. Int. Ed. 2018, 57, 10422-10435. [CrossRef]

189. Perea, D.E.; Arslan, I.; Liu, J.; Ristanović, Z.; Kovarik, L.; Arey, B.W.; Lercher, J.A.; Bare, S.R.; Weckhuysen, B.M. Determining the location and nearest neighbours of aluminium in zeolites with atom probe tomography. Nat. Commun. 2015, 6, 7589. [CrossRef]

190. Delucas, A.; Canizares, P.; Duran, A.; Carrero, A. Dealumination of HZSM-5 zeolites: Effect of steaming on acidity and aromatization activity. Appl. Catal. A Gen. 1997, 154, 221-240. [CrossRef]

191. Schmidt, J.E.; Poplawsky, J.D.; Mazumder, B.; Attila, Ö.; Fu, D.; de Winter, D.A.M.; Meirer, F.; Bare, S.R.; Weckhuysen, B.M. Coke formation in a zeolite crystal during the methanol-to-hydrocarbons reaction as studied with atom probe tomography. Angew. Chem. Int. Ed. 2016, 55, 11173-11177. [CrossRef] [PubMed] 
192. Aramburo, L.R.; Teketel, S.; Svelle, S.; Bare, S.R.; Arstad, B.; Zandbergen, H.W.; Olsbye, U.; de Groot, F.M.F.; Weckhuysen, B.M. Interplay between nanoscale reactivity and bulk performance of H-ZSM-5 catalysts during the methanol-to-hydrocarbons reaction. J. Catal. 2013, 307, 185-193. [CrossRef]

193. Nordvang, E.C.; Borodina, E.; Ruiz-Martínez, J.; Fehrmann, R.; Weckhuysen, B.M. Effects of coke deposits on the catalytic performance of large zeolite H-ZSM-5 crystals during alcohol-to-hydrocarbon reactions as investigated by a combination of optical spectroscopy and microscopy. Chem. Eur. J. 2015, 21, 17324-17335. [CrossRef] [PubMed]

194. Schmidt, J.E.; Peng, L.; Paioni, A.L.; Ehren, H.L.; Guo, W.; Mazumder, B.; de Winter, D.A.M.; Attila, Ö.; Fu, D.; Chowdhury, A.D.; et al. Isolating clusters of light elements in molecular sieves with atom probe tomography. J. Am. Chem. Soc. 2018, 140, 9154-9158. [CrossRef] [PubMed]

195. Devaraj, A.; Vijayakumar, M.; Bao, J.; Guo, M.F.; Derewinski, M.A.; Xu, Z.; Gray, M.J.; Prodinger, S.; Ramasamy, K.K. Discerning the location and nature of coke deposition from surface to bulk of spent zeolite catalysts. Sci. Rep. 2016, 6, 37586. [CrossRef] [PubMed]

196. Danisi, R.M.; Schmidt, J.E.; Paioni, A.L.; Houben, K.; Poplawky, J.D.; Baldus, M.; Weckhuysen, B.M.; Vogt, E. Revealing long- and short-range structural modifications within phosphorus-treated HZSM-5 zeolites by atom probe tomography, nuclear magnetic resonance and powder X-ray diffraction. Phys. Chem. Chem. Phys. 2018, 20, 27766-27777. [CrossRef] [PubMed]

197. Kovarik, L.; Washton, N.M.; Kukkadapu, R.; Devaraj, A.; Wang, A.; Wang, Y.; Szanyi, J.; Peden, C.H.F.; Gao, F. Transformation of active sites in Fe/SSZ-13 SCR catalysts during hydrothermal aging: A spectroscopic, microscopic, and kinetics study. ACS Catal. 2017, 7, 2458-2470. [CrossRef]

198. Göltl, F.; Bulo, R.E.; Hafner, J.; Sautet, P. What makes copper-exchanged SSZ-13 zeolite efficient at cleaning car exhaust gases? J. Phys. Chem. Lett. 2013, 4, 2244-2249. [CrossRef]

199. Kwak, J.H.; Tonkyn, R.G.; Kim, D.H.; Szanyi, J.; Peden, C.H.F. Excellent activity and selectivity of Cu-SSZ-13 in the selective catalytic reduction of $\mathrm{NO}_{x}$ with $\mathrm{NH}_{3}$. J. Catal. 2010, 275, 187-190. [CrossRef]

200. Wang, J.; Zhao, H.; Haller, G.; Li, Y. Recent advances in the selective catalytic reduction of $\mathrm{NOx}_{\text {with }} \mathrm{NH}_{3}$ on Cu-Chabazite catalysts. Appl. Catal. B Environ. 2017, 202, 346-354. [CrossRef]

201. Schmidt, J.E.; Oord, R.; Guo, W.; Poplawsky, J.D.; Weckhuysen, B.M. Nanoscale tomography reveals the deactivation of automotive copper-exchanged zeolite catalysts. Nat. Commun. 2017, 8, 1666. [CrossRef] [PubMed]

202. Schmidt, J.E.; Ye, X.; van Ravenhorst, I.K.; Oord, R.; Shapiro, D.A.; Yu, Y.-S.; Bare, S.R.; Meirer, F.; Poplawsky, J.D.; Weckhuysen, B.M. Probing the location and speciation of elements in zeolites with correlated atom probe tomography and scanning transmission X-ray microscopy. ChemCatChem 2019, 11, 488-494. [CrossRef] [PubMed]

203. Li, T.; Kasian, O.; Cherevko, S.; Zhang, S.; Geiger, S.; Scheu, C.; Felfer, P.; Raabe, D.; Gault, B.; Mayrhofer, K.J.J. Atomic-scale insights into surface species of electrocatalysts in three dimensions. Nat. Catal. 2018, 1, 300-305. [CrossRef]

204. Eley, C.; Li, T.; Liao, F.; Fairclough, S.M.; Smith, J.M.; Smith, G.; Tsang, S.C.E. Nanojunction-mediated photocatalytic enhancement in heterostructured $\mathrm{CdS} / \mathrm{ZnO}, \mathrm{CdSe} / \mathrm{ZnO}$, and $\mathrm{CdTe} / \mathrm{ZnO}$ nanocrystals. Angew. Chem. Int. Ed. 2014, 53, 7838-7842. [CrossRef] [PubMed]

205. Bligaard, T.; Nørskov, J.K.; Dahl, S.; Matthiesen, J.; Christensen, C.H.; Sehested, J. The Brønsted-Evans-Polanyi relation and the volcano curve in heterogeneous catalysis. J. Catal. 2004, 224, 206-217. [CrossRef]

206. Lin, S.; Diercks, C.S.; Zhang, Y.-B.; Kornienko, N.; Nichols, E.M.; Zhao, Y.; Paris, A.R.; Kim, D.; Yang, P.; Yaghi, O.M.; et al. Covalent organic frameworks comprising cobalt porphyrins for catalytic $\mathrm{CO}_{2}$ reduction in water. Science 2015, 349, 1208-1213. [CrossRef] [PubMed]

207. Manthiram, K.; Beberwyck, B.J.; Alivisatos, A.P. Enhanced electrochemical methanation of carbon dioxide with a dispersible nanoscale copper catalyst. J. Am. Chem. Soc. 2014, 136, 13319-13325. [CrossRef] [PubMed]

208. Jiang, K.; Siahrostami, S.; Akey, A.J.; Li, Y.; Lu, Z.; Lattimer, J.; Hu, Y.; Stokes, C.; Gangishetty, M.; Chen, G.; et al. Transition-metal single atoms in a graphene shell as active centers for highly efficient artificial photosynthesis. Chem 2017, 3, 950-960. [CrossRef]

(C) 2019 by the authors. Licensee MDPI, Basel, Switzerland. This article is an open access article distributed under the terms and conditions of the Creative Commons Attribution (CC BY) license (http://creativecommons.org/licenses/by/4.0/). 